\title{
Towards an improved understanding of plasticity, friction and wear mechanisms in precipitate containing AZ91 Mg alloy
}

\author{
Deepak Kumar ${ }^{a}$, Saurav Goel ${ }^{b, c^{*}}$, Nitya Nand Gosvami ${ }^{a}$, Jayant Jain ${ }^{a^{*}}$ \\ aDepartment of Materials Science and Engineering, Indian Institute of Technology, New \\ Delhi, 110016, India \\ ${ }^{\mathrm{b}}$ School of Engineering, London South Bank University, 103 Borough Road, London SE1 \\ OAA, UK
}

${ }^{\mathrm{c}}$ School of Aerospace, Transport and Manufacturing, Cranfield University, Bedfordshire, MK43 0AL, UK

*Corresponding authors: jayantj@iitd.ac.in and GoeLs@LSBU.ac.uk

\section{Abstract:}

This work reports a combined experimental and atomistic simulation study on continuous precipitates (CPs) and discontinuous precipitates (DPs) affecting the scratch induced wear in AZ91 magnesium alloy. Nanoscratching experiments complemented by atomic simulations were performed to understand the directional dependence and origins of plasticity, friction and wear mechanisms as benchmarked to nanocrystalline $\mathrm{HCP}$ magnesium. Post scratch deformation analysis was performed using electron back scattering diffraction, scanning electron microscope and molecular dynamics (MD) simulation. The direction of orientation of the precipitates was observed to make a significant influence on the deformation behaviour. For example, regardless of the precipitates type (CP or DP), a ductile-brittle transition becomes pronounced while scratching along the direction (orientation) of precipitates, whilst a fully ductile response was obtained while scratching along the direction normal to the precipitates. However, regardless of the direction of orientation, DPs showed a higher wear resistance and coefficient of friction compared to the CPs. These observations were supported by the quantitative analysis of the planar defects such as coherent twins, extrinsic and intrinsic stacking faults in the deformation zone as well as $1 / 3<1 \overline{1} 00>$ and $1 / 3<1 \overline{2} 10>$ 
dislocations type extracted from the MD analysis.These observations will facilitate an improved design of AZ91 alloys in particular and intermetallic precipitate containing alloys in general.

Keywords: Mg alloys; precipitates; nano-wear; dislocation; twinning; atomistic simulations

\section{Introduction}

The high specific strength, good casting and welding ability makes magnesium and its alloys an important engineering material for automotive, biomedical and aerospace industries [1-4] . However, the full exploitation of these materials is impeded by several limitations such as-low toughness, poor formability, low creep and corrosion resistance, and poor tribological properties [1,5]. More specifically, in several structural applications, the surface of these alloys frequently comes in contact with counter surfaces during fabrication, assembling and handling, where their tribological behaviour becomes critically important [6]. The friction and wear behavior of magnesium alloys are important in components involving sliding motion, e.g., gears, brakes and engine components including piston-cylinder assembly [7,8]. Among other magnesium alloys, the AZ91 alloy is most widely used due to its relatively high strength and good casting ability. It is well known that mechanical and tribological properties of this alloy can be tuned by incorporating precipitates in the microstructure via aging treatment [9-11]. The aged AZ91 alloy shows two kinds of precipitates i.e. continuous precipitates (CPs) and discontinuous precipitates (DPs) [12]. The formation of CPs occurs near the solvus temperature $\left(350^{\circ} \mathrm{C}\right)$, while DPs forms at lower temperatures (i.e. $\left.\leq 150^{\circ} \mathrm{C}\right)[13]$. A co-existence of both CPs and DPs occurs at intermediate temperatures between $150{ }^{\circ} \mathrm{C}$ to $300{ }^{\circ} \mathrm{C}$. 
The crystal structure of both CPs and DPs is body centered cubic (BCC); however, their morphology and distribution in the surrounding matrix are distinct [14]. Many authors have emphasised on the significance of precipitate morphology (lamellar for DPs vs. non-lamellar for CPs) and their distribution on the bulk mechanical properties and wear response [15-18]. However, information available on the fundamental atomic processes governing the wear of the CP's and DP's is scarce. There is also a limited understanding on how the precipitate morphology, sliding direction and their distribution affects the material removal mechanism, which forms the basis for undertaking this investigation.

Nanoindentation and Nanoscratching techniques are widely used to measure the localised mechanical properties of materials such as hardness, elastic modulus and wear response $[19,20]$. In the past, several studies have been carried out to understand the scratch induced wear behaviour of various materials $[5,11,17]$.

During scratching, several competing mechanisms can trigger (depending on the material type) such as dislocation nucleation and propagation leading to twinning and high-pressure phase transformation may occur at atomic level while shear band formation occurs at a higher length scale. The magnitude and volume density of these material specific mechanisms in particular the volume of dislocations can indicate the extent of plasticity in the material, however it is cumbersome to quantify this using experimental methods such as transmission electron microscope (TEM). In such a case, molecular dynamics (MD) simulation is an appropriate tool to study the dislocation mediated plasticity [21]. In the past, most MD simulation studies about the plasticity and dislocation interactions beneath the surfaces, after indentation and scratch, are directed to the single crystal FCC [22-25] and BCC [26-28] materials. For HCP materials, very few studies are available in the literature [29-31]. Also, the studies related to friction anisotropy with respect to sliding direction are limited. For instance, Alhafez et al. [32] performed indentation using MD simulation for $\mathrm{HCP}, \mathrm{FCC}$ and $\mathrm{BCC}$ materials and reported 
that plastic zone size is significantly larger in HCP materials than FCC and BCC materials. They also used MD simulations [33] to scratch pure $\mathrm{Mg}$ along different crystal orientations and found that scratching direction significantly affects the dislocation based plasticity. Jun et al. [34] reported that dislocation interactions significantly depends on scratch direction.

In the present study, nanoindentation experiments and MD simulations were performed to investigate the scratch induced deformation behavior of DP and CP regions to understand their contact tribology with respect to pure $\mathrm{Mg}$.

\section{Materials and Methods}

\subsection{Sample preparation}

Commercially available as-cast rectangular blocks of pure Mg and AZ91 alloy were used as starting materials (Alfa Aesar, Ward Hill, MA, USA). Wire electrical discharge machining $(\mathrm{EDM})$ was used to cut the block into small cubes of $1 \mathrm{~cm}^{3}$. The samples were then heat treated at $390{ }^{\circ} \mathrm{C}$ for $48 \mathrm{~h}$ in air and then quenched with water to dissolve the precipitates into the matrix. The samples were then aged at $200{ }^{\circ} \mathrm{C}$ for different times and water quenched. Peak hardness $(83 \pm 3 \mathrm{HV})$ was achieved after $35 \mathrm{~h}$ at $200^{\circ} \mathrm{C}$ and the same peak aged samples were selected for further study.

All samples were prepared by polishing on $\mathrm{SiC}$ pads and then subsequently by cloth polishing with colloidal silica medium $(0.05 \mu \mathrm{m}$ size $)$ in presence of the DI water. The samples were etched in $10 \%$ Nital solution followed by rinsing in acetone and drying under a jet of nitrogen gas. Peak aged samples that showed large domains of CP and DP regions were chosen for further study. The area fraction of CP and DP was evaluated through image processing (Image 
J software) and a total ten SEM images of each type of precipitates regions were analysed to ensure good quantitative analysis.

\subsection{Nano-hardness test}

To determine the local mechanical properties of pure $\mathrm{Mg}, \mathrm{CP}$ and $\mathrm{DP}$ regions, a nanoindenter (ASMEC Universal Nanomechanical Tester, Bautzner Landstraße 45, Germany) was used. The measurements were performed using Berkovich diamond probe (tip radius $153 \mathrm{~nm}$ and included angle $140.6^{0}$ ). Quasi-continuous stiffness measurement (QCSM) method was used to measure the hardness [35]. The hardness measurements were performed using a load controlled tests by considering $500 \mathrm{mN}$ load. At this load, significant regions containing both precipitates and matrix were covered under the indenter tip to obtain an average response of precipitates and matrix together. The test was carried out at $500 \mathrm{mN}$ load for a hold time of $10 \mathrm{~s}$. The loading and unloading rates were kept constant at $1 \mathrm{mN} / \mathrm{s}$. A total of twenty five indents were made on pure $\mathrm{Mg}$ and on both type of precipitate regions to ensure the repeatability and average data with standard deviation was obtained. Nano hardness values were determined from loaddisplacement curves by applying the Oliver-Pharr method [36] that relies on using loaddisplacement profiles without measurement of the actual projected contact area postindentation $[37,38]$.

\subsection{Micro-scratching experiments}

Micro-scratch tests were performed on both pure $\mathrm{Mg}$ as well as $\mathrm{CP}$ and $\mathrm{DP}$ regions using ASMEC Universal Nanomechanical Tester (Bautzner Landstraße 45, Germany) with a diamond cono-spherical tip of $\sim 8 \mu \mathrm{m}$ tip radius. A load of $400 \mathrm{mN}$ with a scratch velocity of $5 \mu \mathrm{m} / \mathrm{s}$ was used that resulted in a total scratch length of $200 \mu \mathrm{m}$. A higher load was selected to ensure that the scratch depth was significantly higher than the height of DPs and CPs. As it was a load controlled testing, the contact depth (scratch depth) was not controlled in these tests. 
A minimum of five scratches were made for each type of precipitate regions and pure $\mathrm{Mg}$ to confirm good reproducibility.

\subsection{Surface characterisation}

The geometric characterisation of discontinuous and continuous precipitates was performed by an Atomic force microscope (Nanosurf Flex Axiom, Switzerland). The Optical 3D Profilometer (MACWIN Zeta 20, California, USA) was used to examine the cross-sectional area and pile up formed during each micro-scratch experiment. For each type of precipitate regions, at least five scratches were examined, and for each scratch, four different regions were taken in orthogonal direction of the scratch, therefore an average of $20(5 \times 4)$ cross sectional areas for each type of precipitate regions as well as pure $\mathrm{Mg}$ were analysed. Wear volumes of the scratches were calculated by multiplying the cross-sectional areas of individual scratch with the corresponding scratch length. A tabletop scanning electron microscope (SEM) (Hitachi, TM3000, Tokyo, Japan) was used to image the scratched regions in the material immediately after the micro scratch tests for all the samples.

Electron backscattering diffraction (EBSD) (JEOL, JSM, 7800f, Oxford) was used to reveal the deformation behavior post scratch testing. All EBSD maps were taken using field emission scanning electron microscope (FESEM) operated at an accelerated voltage of $20 \mathrm{kV}$. The EBSD map was captured at a step size of $0.5 \mu \mathrm{m}$ and $1 \times 1$ binning for pure $\mathrm{Mg}, \mathrm{CP}$ and $\mathrm{DP}$ regions. The piled up material near the edge of scratches was carefully removed by polishing to observe scratch induced plasticity.

\subsection{MD simulation setup}

The MD simulations were performed using an open source code LAMMPS, the "Large-scale atomic/molecular massively parallel simulator" ( $3^{\text {rd }}$ July 2018 version) [39] and OVITO [40] 
was used to visualize and analyse the results. Furthermore, the automated "dislocation extraction algorithm" (DXA) $[41,42]$ within OVITO was used for identification of dislocations and other crystal defects.

Prior to the simulation work, various potential functions (force-fields) available in the literature were examined for describing the two phases of the materials namely, hexagonal close packed pure magnesium, and beta $\mathrm{Mg}_{17} \mathrm{Al}_{12}$ (CP and DP's). From a first glance of the literature, it was found that there are a number of choices available such as EAM potential (alloy type) proposed by Liu et al. [43], EAM potential (Finnis-Sinclair type) proposed by Mendelev et al. [44], MEAM potential function proposed by Jelinek et al. [45] and MEAM (2NN) proposed by CALPHAD group [46]. Out Of these potentials, the Mendelev's Finnis Sinclair potential type EAM was chosen in the study for it being able to estimate the stacking fault energy for $<a>$ edge basal dislocations in $\mathrm{Mg}$ as $35 \mathrm{~mJ} / \mathrm{m}^{2}$ close to DFT predictions of $37 \mathrm{~mJ} / \mathrm{m}^{2}$ [47]. We then checked the robustness of the Mendelev's potential [44] in reproducing the elastic constants and other relevant mechanical properties of both $\mathrm{HCP}$ pure magnesium and beta $\mathrm{Mg}_{17} \mathrm{Al}_{12}$. Some of these properties, like the equilibrium lattice parameter, Young's modulus on the three crystallographic planes, bulk modulus, shear modulus and shear strength at $0 \mathrm{~K}$, are listed in Table I included as appendix $[44,48]$.

Using this potential, a dummy simulation study was performed to cut pure $\mathrm{Mg}$ both on prismatic and basal planes. It was observed that prismatic surface of $\mathrm{Mg}$, not being the minimum energy surface, undergoes significant surface reconstruction, whilst basal plane gave a more stable configuration. Therefore, the simulations here report cutting on the basal plane i.e. direction normal out of the basal plane is $\mathrm{Y}$ axis of the simulation (shown in Figure 1a). The unit cell of HCP magnesium $(\mathrm{a}=0.319891 \mathrm{~nm})$ contains $4 \mathrm{Mg}$ basis atoms (two atoms in the $\mathrm{z}=0$ plane and two atoms in the $\mathrm{z}=0.5$ plane) while the unit cell of beta $\mathrm{Mg}_{17} \mathrm{Al}_{12}$ containing $34 \mathrm{Mg}$ and $24 \mathrm{Al}$ basis atoms is shown in Figure 1 (b) \& (c), respectively. A velocity 
controlled constant depth scratch simulations were done by taking a scratch depth of $2 \mathrm{~nm}$ and scratch velocity of $100 \mathrm{~m} / \mathrm{s}$ in all the simulations.

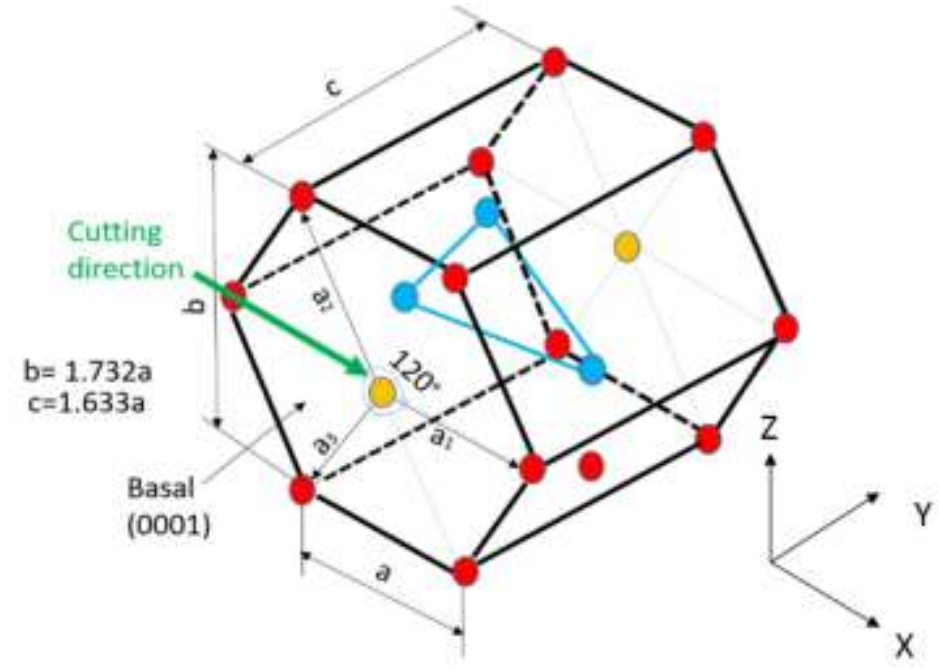

(a)

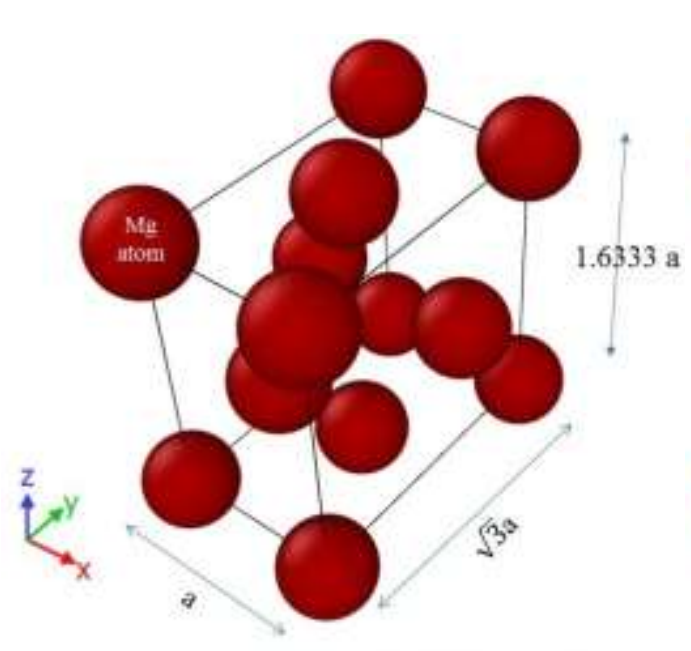

(b)

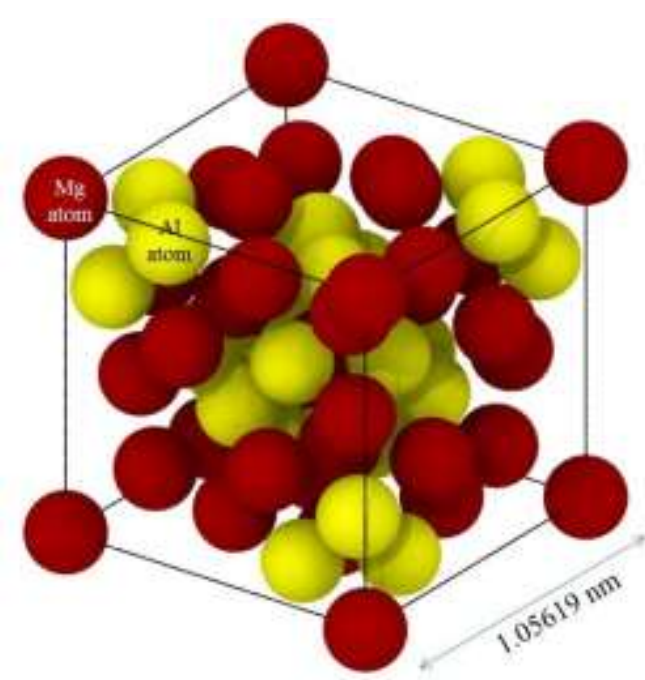

(c)

Figure 1. Schematic illustration of (a) a HCP unit cell and direction of cutting on the basal plane, (b) unit cell of HCP magnesium $(\mathrm{a}=0.319891 \mathrm{~nm}$ ) containing $4 \mathrm{Mg}$ basis atoms (two atoms in the $\mathrm{z}=0$ plane and two atoms in the $\mathrm{z}=0.5$ plane) (c) unit cell of beta $\mathrm{Mg}_{17} \mathrm{Al}_{12}$ containing $34 \mathrm{Mg}$ and $24 \mathrm{Al}$ basis atoms. $\mathrm{Mg}$ atoms are colored in red whilst aluminum atoms are colored in yellow.

For achieving the near experimental scale, the geometric build of the beta $\mathrm{Mg}_{17} \mathrm{Al}_{12}$ precipitates 
in the simulation followed the scaled down AFM measurements. For both CPs and DPs, the orientation relationship $(0001)_{\mathrm{H}} / /(001)_{\mathrm{B}},[2 \overline{1} \overline{1} 0] / /[1 \overline{1} 1]$ is the same [49] and was taken into account in simulation. In this process, we discovered that both type of precipitates are usually plate shaped. The CPs and DPs protrudes out of the surface of the substrate by about 90 to 100 $\mathrm{nm}$ and 150 to $170 \mathrm{~nm}$ and are embedded about 80 to $90 \mathrm{~nm}$ and 130 to $160 \mathrm{~nm}$ deeply into the material matrix, respectively. The length of CPs and DPs were estimated to be 5000 to 6000 $\mathrm{nm}$ and 2200 to $3500 \mathrm{~nm}$ and about 300 to $350 \mathrm{~nm}$ and $360 \mathrm{~nm}$ to $450 \mathrm{~nm}$ wide, respectively. The inter particle spacing from surface to surface for CP and DP regions was about 1100 to $1500 \mathrm{~nm}$ and 140 to $170 \mathrm{~nm}$, respectively.

Figure 2 shows the schematic illustration of pure $\mathrm{Mg}$, DP and CP regions assumed in MD simulation to perform scratch. Unfortunately, the size of experiment as seen by the AFM to be achieved by the MD is still computationally prohibitive even by using the large workstations and therefore, we scaled down the size of precipitates. Following the assessment from AFM, an MD simulation scratch model was developed with suitable boundary conditions. In the MD model, the atoms in the workpiece were divided into three distinct zones, namely boundary atoms, thermostatic atoms and Newton atoms. The atoms in the Newton region, which is directly affected by the tool-workpiece interaction, followed Newtonian dynamics (NVE dynamics), while atoms in a thin boundary layer were subjected to a thermostat to dissipate the heat generated in the cutting region, which, in experiment, is dissipated by air or lubricant. Atoms at the outermost boundary of the model were fixed to keep the workpiece in place. A force-field providing interaction of carbon atoms (diamond indenter) with $\mathrm{Mg}$ and al atoms is not readily available and therefore, an imaginary spherical shaped rigid indenter of radius $\mathrm{R}=$ $5 \mathrm{~nm}$, described by a potential with a repulsive force constant $\mathrm{F}(\mathrm{r})=-\mathrm{K}(\mathrm{r}-\mathrm{R})^{2}$ where $\mathrm{K}$ is 2 $\mathrm{keV} / \AA^{3}=3204 \mathrm{nN} / \AA^{2}=320.4 \mathrm{TPa}$, was modelled to mimic a spherical probe. This assumption has some implications of underestimating the cutting forces but it is a reasonable choice 
$[37,48]$. After equilibration of the model at $300 \mathrm{~K}$, the repulsive indenter was prescribed a constant velocity of $100 \mathrm{~m} / \mathrm{s}$ to move a total distance of $32.984 \mathrm{~nm}$ of which $31.984 \mathrm{~nm}$ was through the workpiece. Further details of the MD simulation model are shown in Table II for reproducibility.

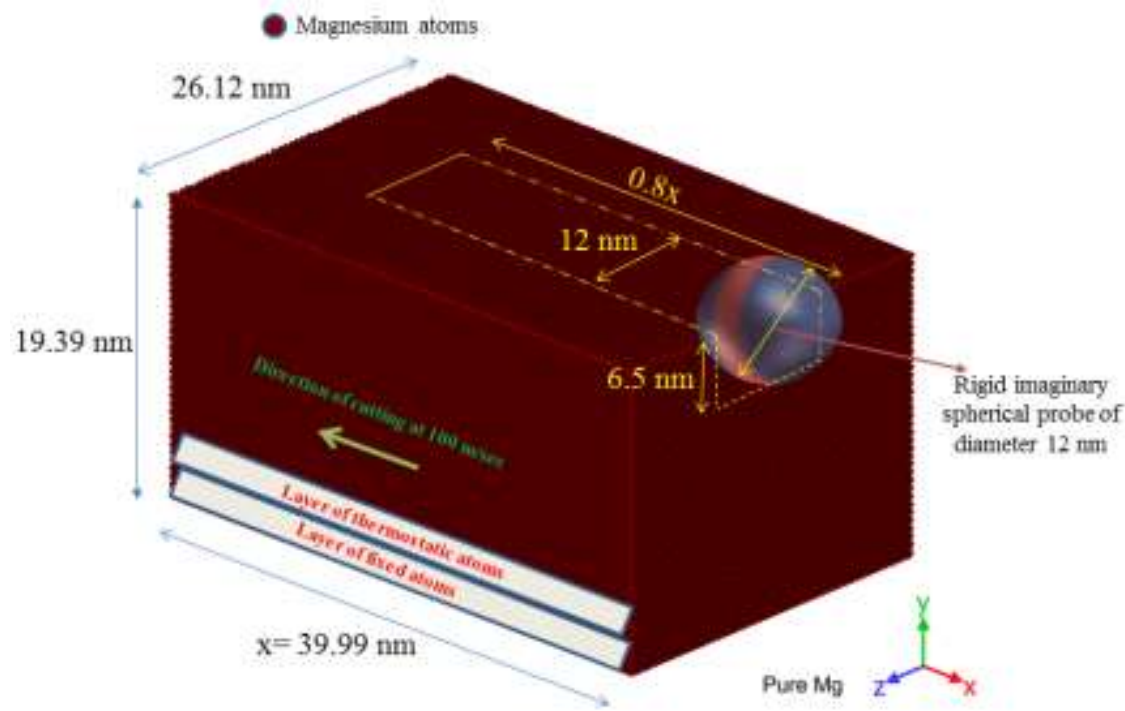

(a)

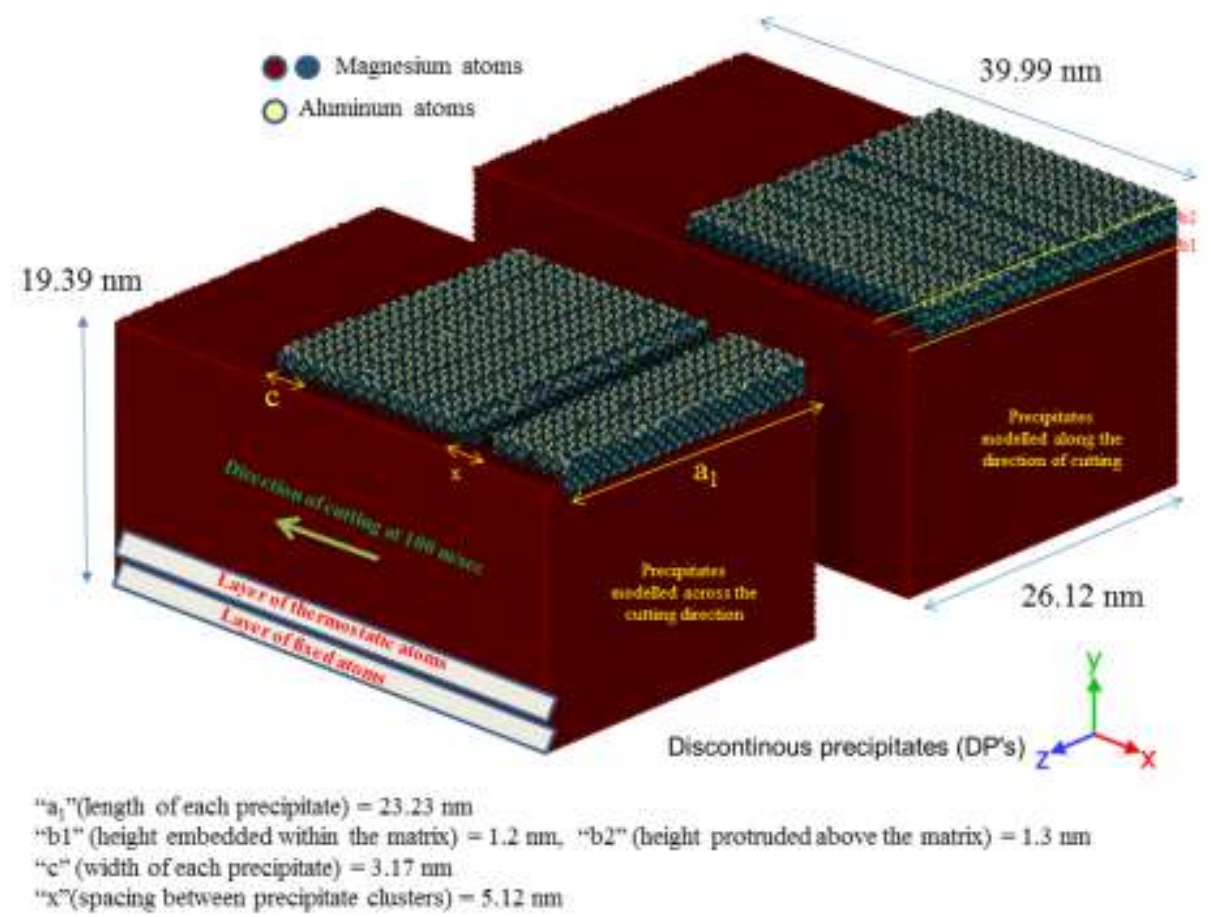

(b) 


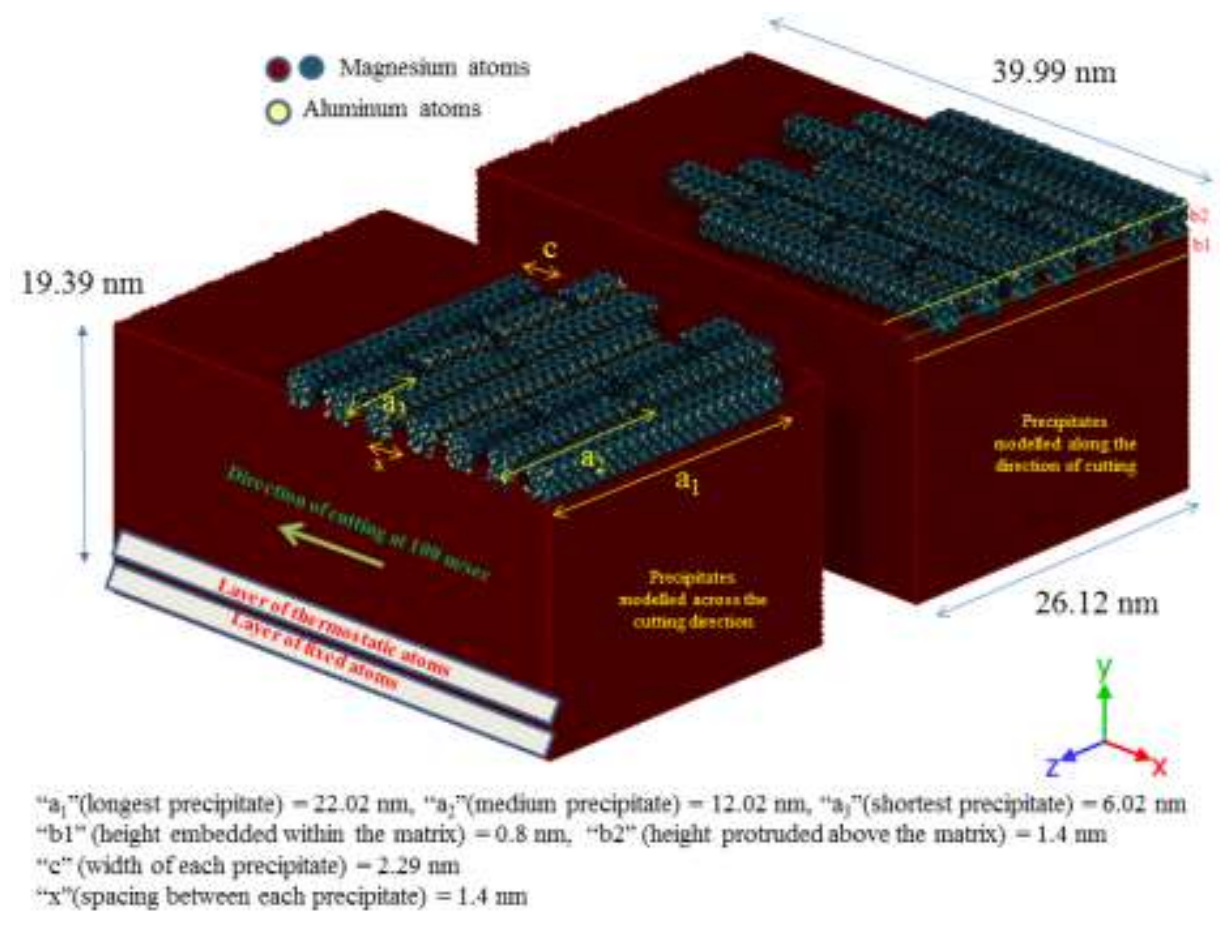

(c)

Figure 2. Schematic illustration of the three cases studied (a) pure Mg cut on a particular cutting direction without any precipitates, (b) DP regions cut across and along the direction of precipitates and (c) CP regions cut across and along the direction of precipitates.

Table II: Process variables and details of the MD simulation model

\begin{tabular}{|c|c|}
\hline Workpiece dimensions & $\begin{array}{l}\text { Mg matrix: } 39.98 \mathrm{~nm} \times 16.06 \mathrm{~nm} \times 26.12 \mathrm{~nm} \text {, } \\
\text { with beta } \mathrm{Mg}_{17} \mathrm{Al}_{12} \text { precipitate of size } 23.23 \mathrm{~nm} \times \\
3.168 \mathrm{~nm} \times 2.11 \mathrm{~nm} \text { with interspacing of about } 1 \\
\mathrm{~nm} \text {. }\end{array}$ \\
\hline Depth of scratch $(d)$ & $2 \mathrm{~nm}$ \\
\hline Cutting tool & $\begin{array}{l}\text { A rigid and frictionless imaginary spherical } \\
\text { indenter of diameter } 12 \mathrm{~nm} \text { described by a } \\
\text { potential with a repulsive force constant } \mathrm{F}(\mathrm{r})=- \\
\mathrm{K}(\mathrm{r}-\mathrm{R})^{2} \text { where } \mathrm{K} \text { is } 2 \mathrm{keV} / \AA^{3}=3204 \mathrm{nN} / \AA^{2}= \\
320.4 \mathrm{TPa}\end{array}$ \\
\hline
\end{tabular}




\begin{tabular}{|l|l|}
\hline Cutting distance (free travel + cutting & $(1+31.984) \mathrm{nm}=32.984 \mathrm{~nm}$ \\
length) & $100 \mathrm{~m} / \mathrm{s}=0.1 \mathrm{~nm} / \mathrm{ps}$ \\
\hline Velocity of the tool & $32.984 \mathrm{~nm} / 0.1 \mathrm{~nm} / \mathrm{ps}=329.8 \mathrm{ps}$ \\
\hline Total simulation time & $1 \mathrm{fs}=1 \times 10^{-3} \mathrm{ps}$ \\
\hline MD Timestep & $329.8 / 0.001=329,891$ \\
\hline Total run timesteps & \\
\hline
\end{tabular}

\section{Results and Discussion}

\subsection{Microstructure characterisation}

An optical micrograph of pure $\mathrm{Mg}$ is shown in Figure 3 (a). A close up view of this, captured using SEM, highlighting the DP and CP regions, is shown in Figure 3(b) and 3 (c), respectively. The area fraction of precipitates in DP and CP regions is $0.52 \pm 0.06$ and $0.28 \pm 0.04$, respectively. It was noticed that DP regions were significantly harder (1.23 $\pm 0.04 \mathrm{GPa})$ as compared to $\mathrm{CP}$ regions $(1.04 \pm 0.05 \mathrm{GPa})$, and pure $\mathrm{Mg}$ that showed least hardness $(\approx 0.41 \pm 0.09$ $\mathrm{GPa})$.
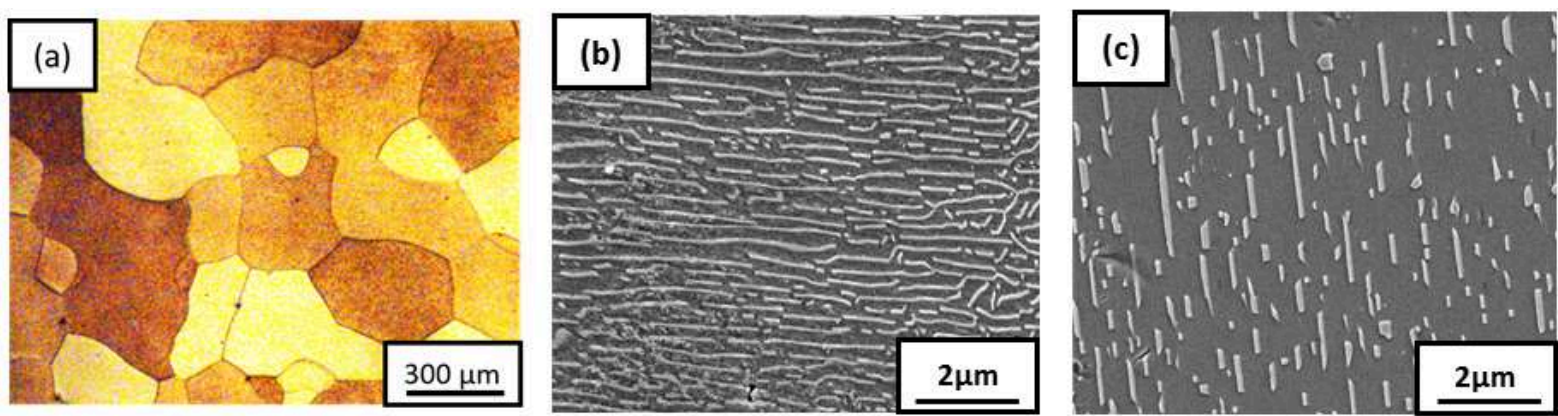

Figure 3. Microstructures of (a) as cast pure Mg, (b) DP regions and (c) CP regions. 


\subsection{Nanoscratch tests}

A comparison of pile up, wear depth and wear volume were made between pure $\mathrm{Mg}, \mathrm{CP}$ and DP regions, using a 3D profilometer imaging post scratch testing. Single pass scratching was employed for both types of precipitate regions and pure $\mathrm{Mg}$. The 3D images of pure $\mathrm{Mg}, \mathrm{CP}$ and DP regions are shown in Figure 4 (a-c). From the colour contrast, it can be observed that the extent of pile up and chip formation for pure $\mathrm{Mg}$ was more than the $\mathrm{CP}$ regions. On the other hand, the pile up and chip formation for DP regions was negligible. An imaginary white line was drawn across the cross section to estimate the wear depth and volume on the section. The overlaid plots in Figure $5(a-b)$ shows that the wear depth and wear volume in case of pure $\mathrm{Mg}$ was higher than CP and DP regions. The wear depth and wear volume of DP regions is significantly lower than the $\mathrm{CP}$ regions due to its high relative hardness. This is consistent with Archard's equation [50] which suggests that at same load, a relatively higher hardness material should have lower wear volume. Also, the movement of dislocation beneath the surfaces is hindered due to the presence of precipitates in the microstructure [51] and thus precipitates regions showed lesser wear than pure $\mathrm{Mg}$.

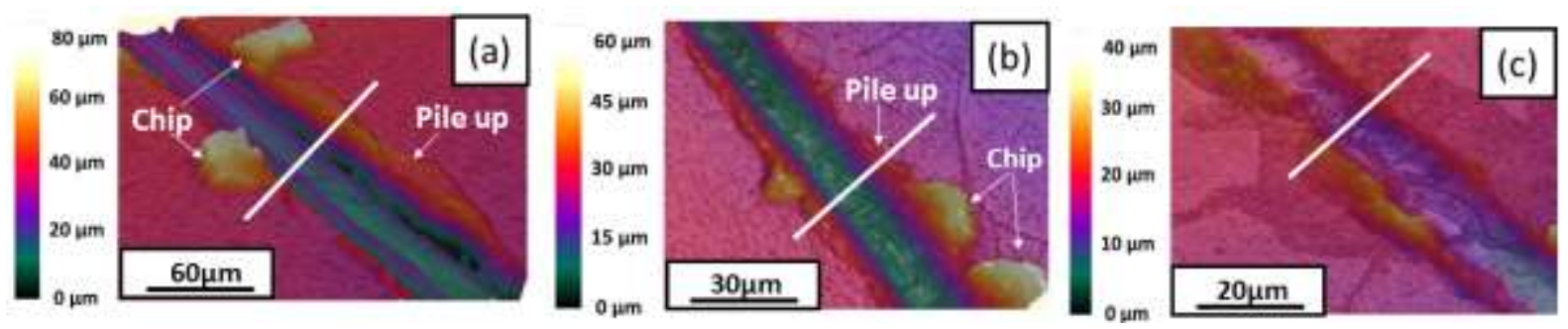

Figure 4. 3D optical profilometry image of (a) pure $\mathrm{Mg}$, (b) CP and (c) DP regions. (White line is the region considered for obtaining the cross section profile). 

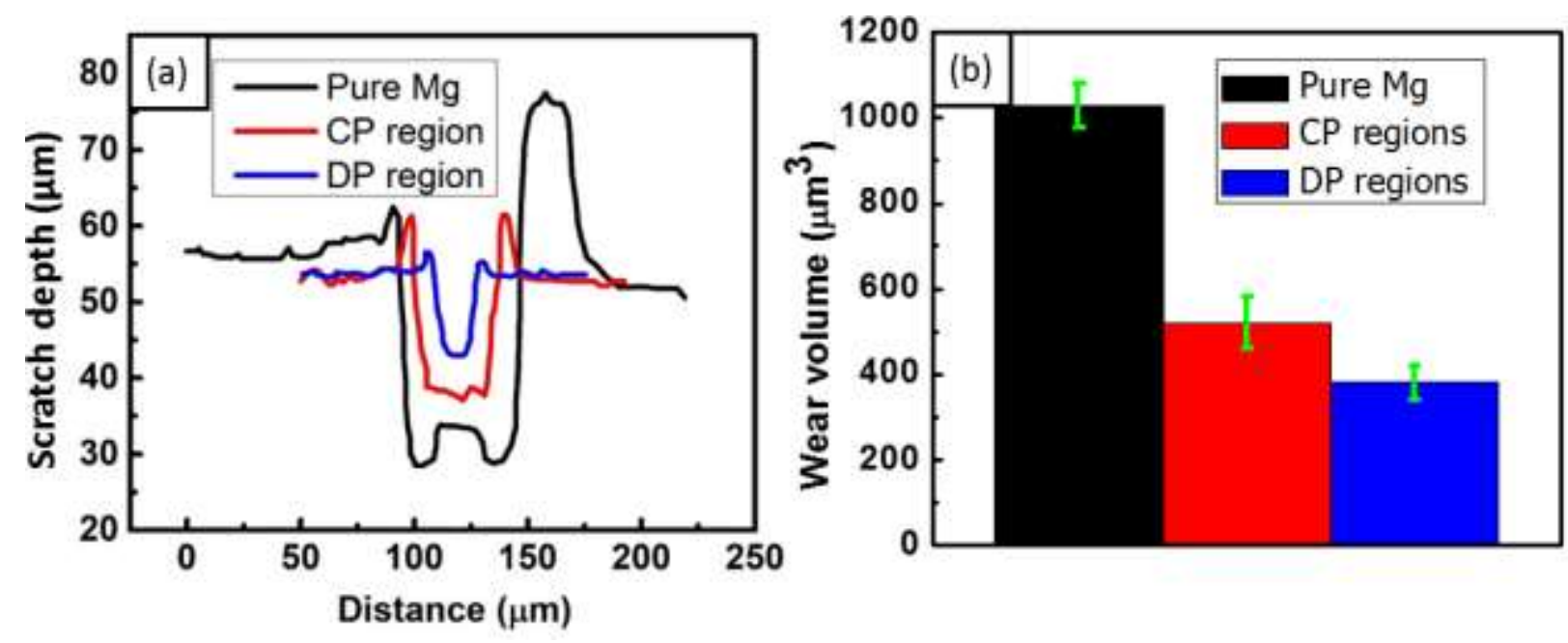

Figure 5. (a) Scratch depth and (b) wear volume of pure Mg, CP and DP regions.

\subsection{SEM and EBSD analysis of wear tracks}

The wear tracks of pure $\mathrm{Mg}, \mathrm{CP}$ and DP regions are illustrated in Figure 6 (a-c), respectively. In case of pure $\mathrm{Mg}$, slip lines as well as twins and pile up at the edges were observed (Figure 6 a). In addition, long chip formation at the end of the wear track and near the edges of the scratch was also observed (Figure 6a). The slip in case of CP and DP regions is obstructed due to the precipitates in these regions and the observation is consistent with the previous study [51]. Pile up at the edges of scratch, long length chip formation at the end of the scratch and smaller cracks are the main deformation mechanisms observed in case of $\mathrm{CP}$ regions as shown in Figure 6b. Deformation mechanisms in DP regions include severe cracking of the material at the edges as well as in scratch groove as shown in Figure 6c. Liu et al. [52] concluded that the DP regions increased the yield and tensile strength but caused reduction in ductility in case of the AZ80 magnesium alloy at $423 \mathrm{~K}$. The reduction in ductility of DP regions can be the cause of severe cracking observed in Figure 6c. 

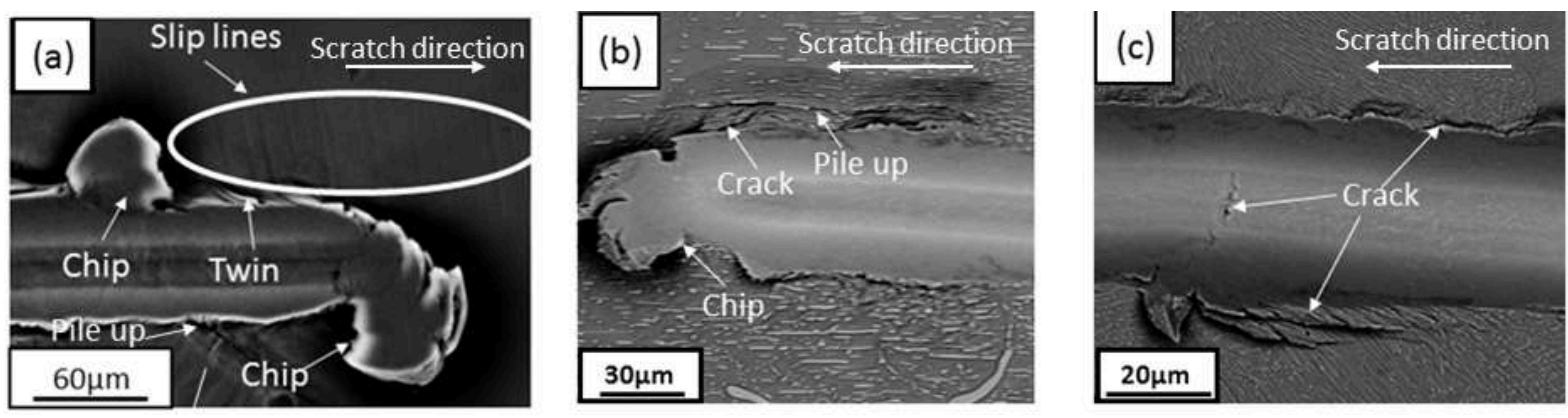

Figure 6. Wear tracks post-scratch for (a) pure Mg, (b) CP and (c) DP regions.

Figure 7 (a-c) shows the EBSD analysis revealing the mechanics of material removal in scratch tests performed in this study. The extension twin boundaries are shown as red boundaries (boundaries misorientation angle $=86^{\circ} \pm 5^{\circ}$ ). It can be seen that the most prominent mode of twinning was $\{10 \overline{1} 2\}<\overline{1} 011>$ extension twin. These twins were fewer in numbers as incorporation of precipitates in the microstructure increase the threshold stress of twinning. (Figure $7 \mathrm{~b}$ and $7 \mathrm{c}$ ). The twinning activity in DP regions was completely supressed due to higher area fraction of precipitates. Also, the grain size in aged AZ91 alloy $(62 \pm 13 \mu \mathrm{m})$ was less as compared to pure $\mathrm{Mg}(405 \pm 36 \mu \mathrm{m})$ and lesser grain size was also a possible reason for suppression of twinning in aged AZ91 alloy. However, the peak aged sample microstructure had precipitates over the entire domain and thus we expect that precipitates are playing a major role to supress the twinning activity over grain boundaries. The results are consistent with previous papers suggesting suppression of $\{10 \overline{1} 2\}$ twinning due to precipitation and grain size [53-56]. Further insights on these came from the MD simulations as discussed in the next section. 

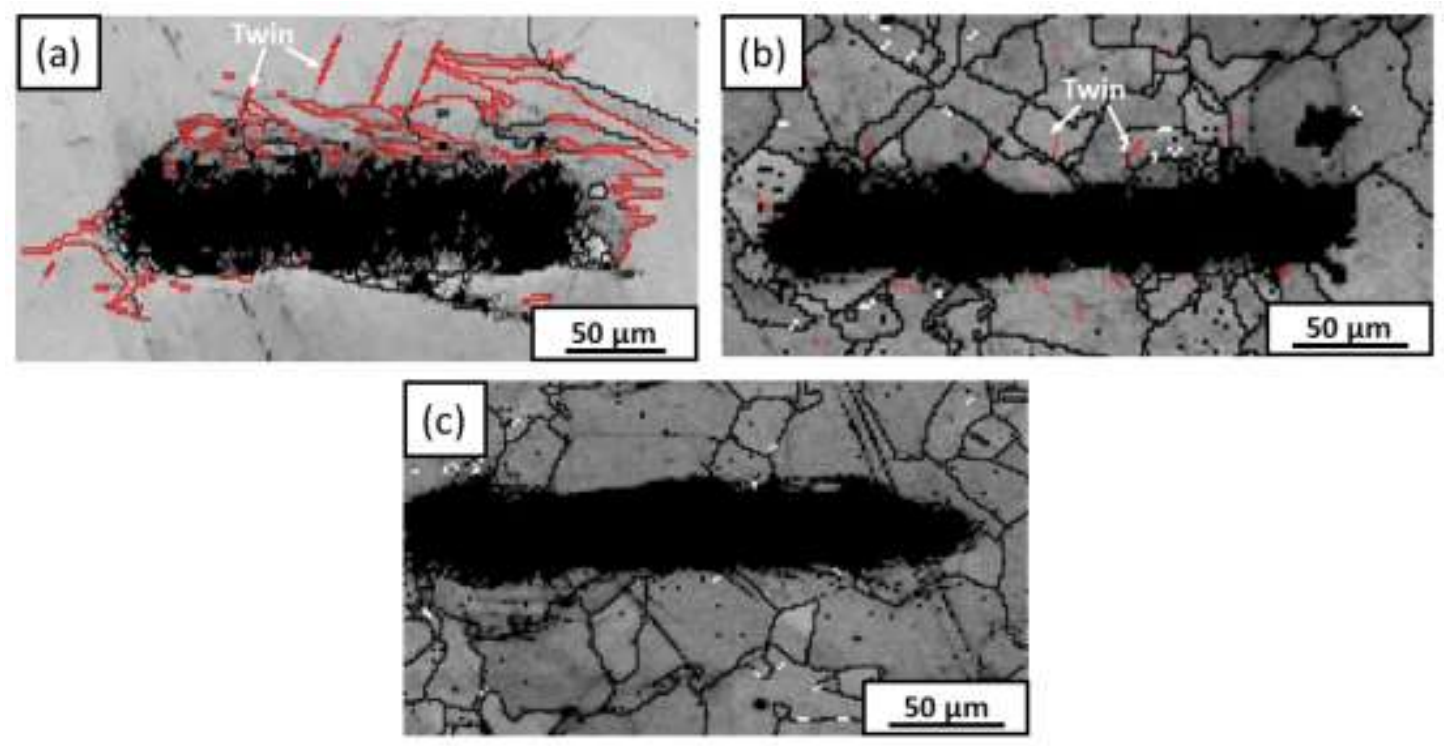

Figure 7. EBSD band contrast images of (a) pure $\mathrm{Mg}$, (b) CP and (c) DP regions showing twins (red boundaries) post scratch.

\subsection{Nanoscratch MD simulations}

\subsubsection{Dislocation nucleation}

Figure 8 shows the sub-surface activities and the depth of plastic region while scratching pure $\mathrm{Mg}$ at two different instances. Illustrative view of the dislocation structure obtained using Crystal Analysis Tool (CAT) showed metastable transformation of HCP atoms of Mg to FCC core atoms within the dislocation structures (green coloured atoms). The primary slip system in HCP metals is $(0001)<11 \overline{2} 0>$ i.e. slip occurs preferentially on the $(0001)$ plane along the $<11 \overline{2} 0>$ direction. In accord with this, the recent literature suggests [33], that a perfect dislocation with Burgers vector $b=1 / 3<\overline{2} 110>$ is common in HCP as it points along the nearest neighbour direction and that it can split into partials with Burgers vector $b=1 / 3<$ $\overline{1} 100>$. The CAT analysis revealed that a prismatic half-loop emerged (visible in the foreground of Figure 8) in the form of a large dislocation loop (especially in pure $\mathrm{Mg}$ ). The Burgers vector (b) of the loop was $1 / 3<1 \overline{2} 10>$. Also, the Burgers vector was oriented 
perpendicular to the loop's habit plane (parallel to the scratching direction) and the green segments were pure edge dislocations pushing the material in the wake of the scratching force. Thus, edge dislocations in the MD simulations were observed to be the medium for the irreversible, plastic transport of material (see attached supplementary videos). It was noticed that several split edge $a$-dislocation of type $\mathbf{b}=1 / 3<1 \overline{2} 10>$ dissociates into $\mathbf{b}=1 / 3<$ $1 \overline{1} 00>$ type. Some parts of the dislocation loop, especially on the basal plane, split into partials (as shown in orange segments). The dissociation reaction was observed to be as follows: $1 / 3[2 \overline{1} \overline{1} 0]$ (green segments of loop) $=1 / 3[10 \overline{1} 0]+1 / 3[1 \overline{1} 00]$ (orange segments of loop).
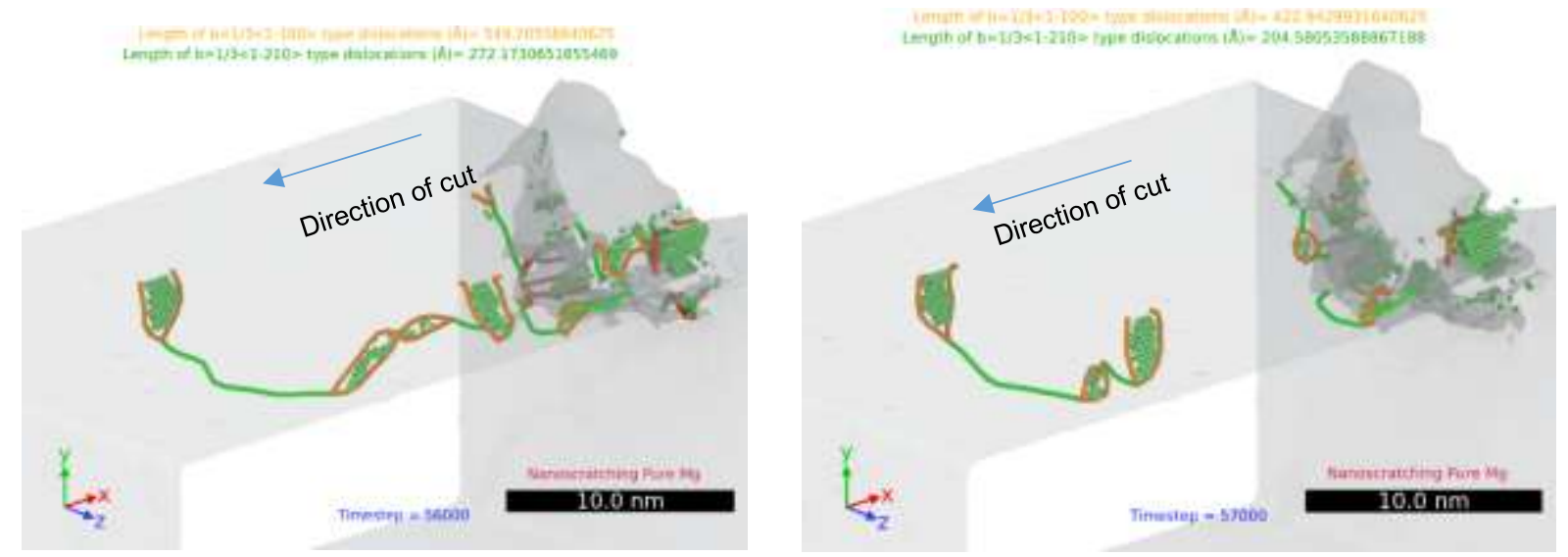

Figure 8. Isometric view of nanoscratching simulations of pure $\mathrm{Mg}$ obtained from DXA algorithm showing two instances of the evolution of dislocation nucleation and propagation in the direction of cutting. Dislocations with $\mathbf{b}=1 / 3<1 \overline{1} 00>$ are shown in orange and $\mathbf{b}=1 / 3<$ $1 \overline{2} 10>$ are shown in green. The unidentified dislocations are shown in red colour. The HCP atoms and surface atoms were removed using DXA tool, while the green atoms visible in the visualization are defective atoms (transformed metastable phases discussed later).

Figure 9 and 10 shows a similar analysis performed during the nanoscratching but in the presence of DP and CP regions (considering the direction of precipitates i.e. cutting across and along the precipitates), respectively. The extent of dislocation-mediated plasticity in the presence of DP regions reduced significantly compared to scratching of pure Mg. In particular, the cutting of DP region across the precipitates seemed to result in the strongest scratch 
resistance.

Other miscellaneous dislocations (red colour) were also seen especially during scratching of CP's across the precipitates were of type $1 / 18$ [04 $\overline{4} \overline{3}]$ joined by $1 / 18[\overline{4} \overline{2} 6 \overline{3}]$. The total number of segments and the total length of the dislocations generated in the three cases were different and this gives an idea on how the extent of plasticity vary in all the three cases.

Measurement of maximum vertical distance of the dislocation loop from the surface of the substrate is a direct indicator of the extent of plasticity induced in the substrate by the indenter, which reveals the difference in the degree of plastic work in the sub-surface. While scratching pure $\mathrm{Mg}$, and $\mathrm{CP}$ and $\mathrm{DP}$ regions across and along the direction of cut then two major types of dislocations with Burgers vectors $1 / 3<1 \overline{1} 00>$ and $1 / 3<1 \overline{2} 10>$ were observed. Table III shows the dislocation length for the Burgers vector $1 / 3<1 \overline{1} 00>$ and $1 / 3<1 \overline{2} 10>$ for pure $\mathrm{Mg}$, DP and CP regions across and along scratching direction.

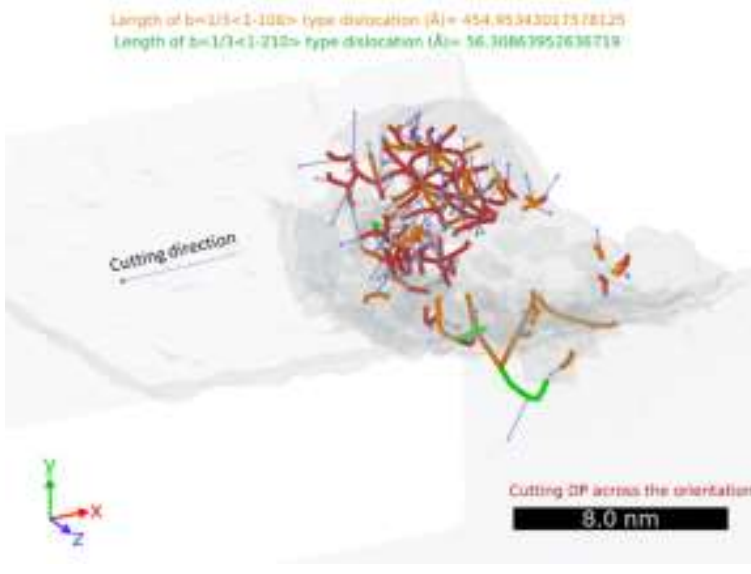

(a)

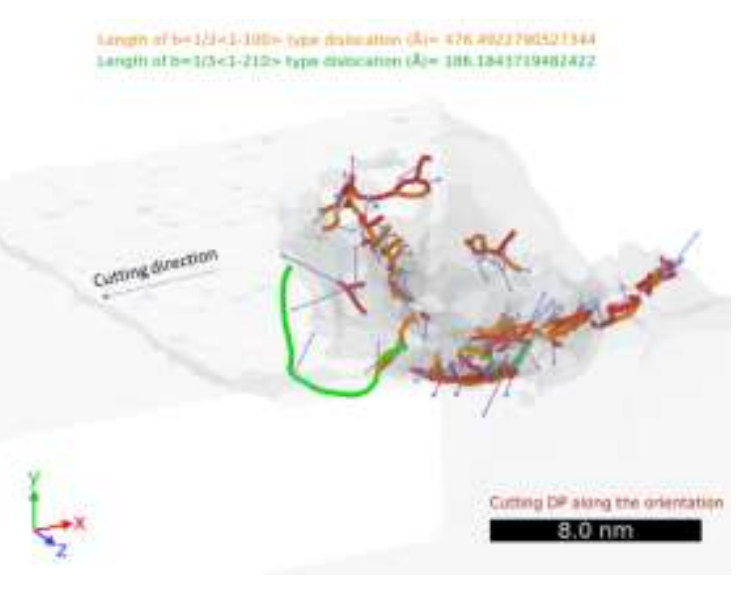

(b)

Figure 9. Isometric view of nanoscratching simulations showing directional dependency during cutting the Mg crystal with the presence of DP regions at two instances (a) when cutting was performed across the precipitates and (b) when cutting was performed along the direction of precipitates. Dislocations with $b=1 / 3<1 \overline{1} 00>$ are shown in orange and $b=1 / 3<1 \overline{2} 10>$ are shown in green. The unidentified dislocations are shown in red colours. The HCP atoms and surface atoms were removed using DXA tool. 


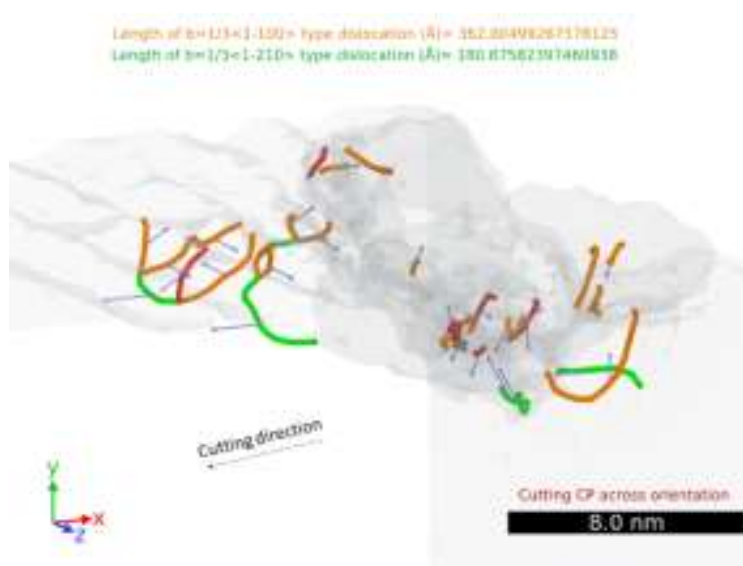

(a)

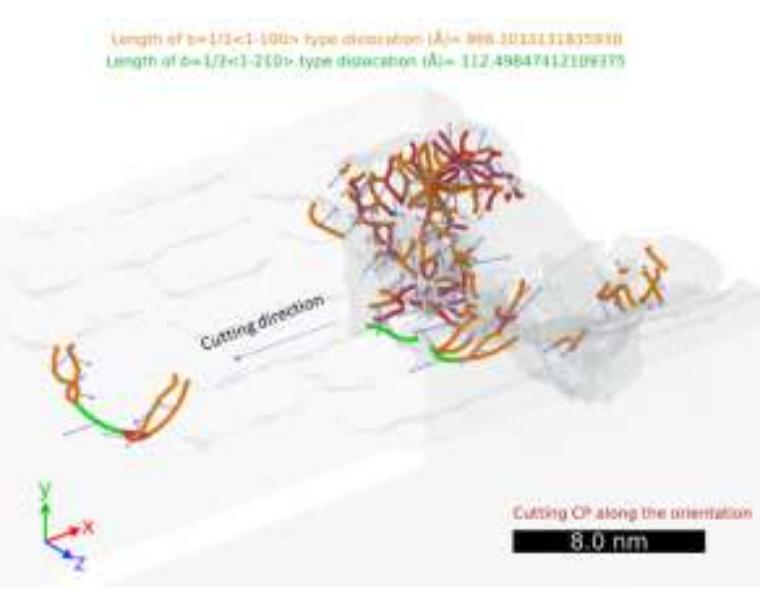

(b)

Figure 10. Isometric view of nanoscratching simulations showing directional dependency during cutting the Mg crystal with the presence of CP regions (a) when cutting was performed across the precipitates and (b) when cutting was performed along of precipitates. Dislocations with $b=1 / 3<1 \overline{1} 00>$ are shown in orange and $b=1 / 3<1 \overline{2} 10>$ are shown in green. The unidentified dislocations are shown in red colour. The HCP atoms and surface atoms were removed using DXA tool.

Table III: Burgers vector of the dislocation observed during the MD simulation

\begin{tabular}{|c|c|c|}
\hline Simulation case & Scratching condition & $\begin{array}{c}\text { Type of dislocations (Burgers } \\
\text { vector) }\end{array}$ \\
\hline Pure Mg & $\begin{array}{l}\text { Cutting performed on the } \\
\text { basal plane along the ' } \mathrm{X} \text { ' } \\
\text { direction }\end{array}$ & $\begin{array}{l}\text { Total dislocation lengths with } \mathrm{b}=1 / 3 \\
<1 \overline{1} 00>\text { (orange colour) about } \\
\sim 77 \mathrm{~nm} \text { and } \mathrm{b}=1 / 3<1 \overline{2} 10>\text { (green } \\
\text { colour) of about } \sim 26 \mathrm{~nm}\end{array}$ \\
\hline DP regions & Across the precipitates & $\begin{array}{l}\mathrm{b}=1 / 3<1 \overline{1} 00>\text { (orange colour) of } \\
\text { about } \sim 45 \mathrm{~nm} \text { and } \mathrm{b}=1 / 3<1 \overline{2} 10> \\
\text { (green colour) of about } \sim 6 \mathrm{~nm}\end{array}$ \\
\hline
\end{tabular}




\begin{tabular}{|c|c|c|}
\hline & Along the precipitates & $\begin{array}{l}\mathrm{b}=1 / 3<1 \overline{1} 00>\text { (orange colour) of } \\
\text { about } \sim 48 \mathrm{~nm} \text { and } \mathrm{b}=1 / 3<1 \overline{2} 10 \\
>\text { (green colour) of about } \sim 19 \mathrm{~nm}\end{array}$ \\
\hline \multirow[t]{2}{*}{$\mathrm{CP}$ regions } & Across the precipitates & $\begin{array}{l}\text { Total dislocation lengths with } \mathrm{b}=1 / 3 \\
<1 \overline{1} 00>\text { (orange colour) about } \\
\sim 36 \mathrm{~nm} \text { and } \mathrm{b}=1 / 3<1 \overline{2} 10>\text { (green } \\
\text { colour) of about } \sim 18 \mathrm{~nm} \text {. Additional } \\
\text { dislocations of type } 1 / 18 \quad[04 \overline{4} \overline{3}] \\
\text { joined by } 1 / 18[\overline{\overline{4}} \overline{2} 6 \overline{3}] \text { were also } \\
\text { seen. }\end{array}$ \\
\hline & Along the precipitates & $\begin{array}{l}\text { Total dislocation lengths with } \mathrm{b}=1 / 3 \\
<1 \overline{1} 00>\text { (orange colour) about } \\
\sim 96 \mathrm{~nm} \text { and } \mathrm{b}=1 / 3<1 \overline{2} 10>\text { (green } \\
\text { colour) of about } \sim 11 \mathrm{~nm} \text {. }\end{array}$ \\
\hline
\end{tabular}

\subsubsection{Planar defects}

A detailed view of the deformation zone while scratching DP's and CP's is shown in Figure 11 and Figure 12 respectively. 


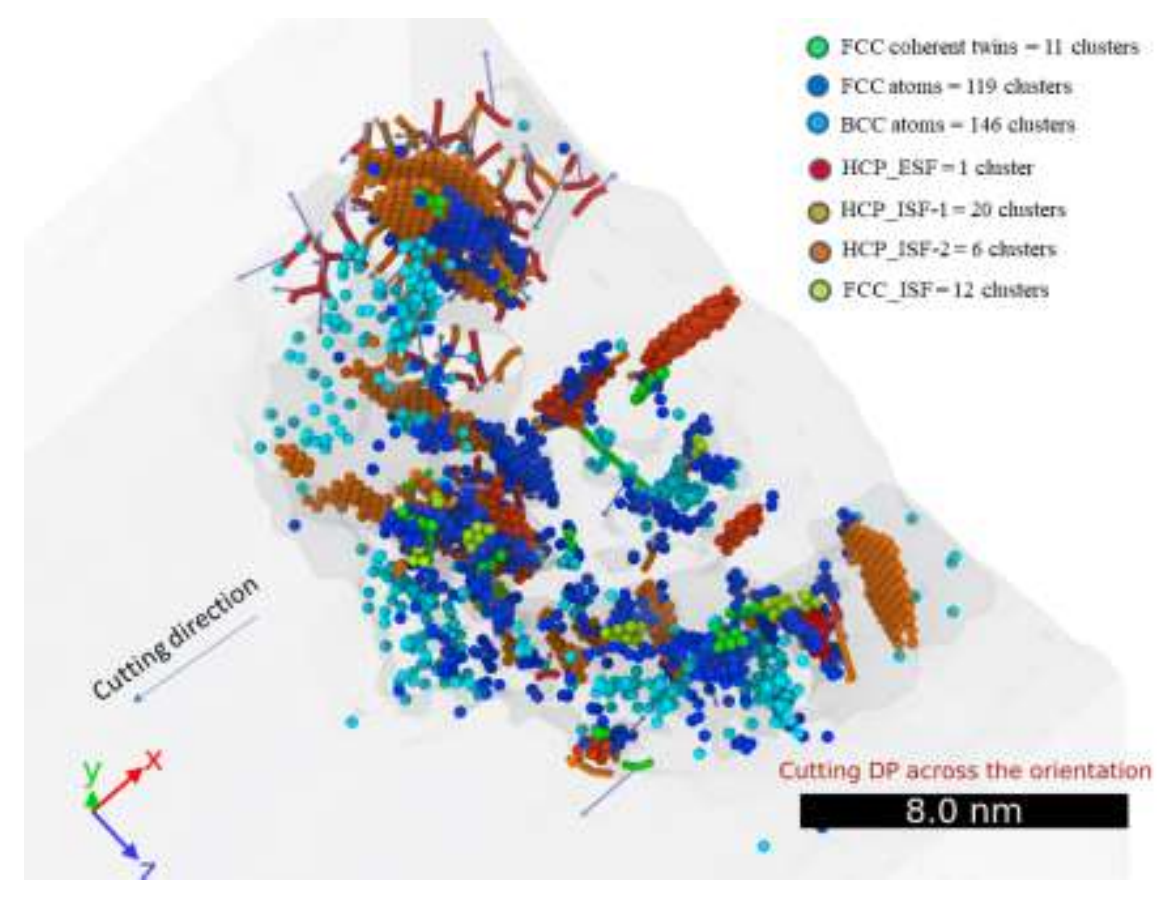

(a)

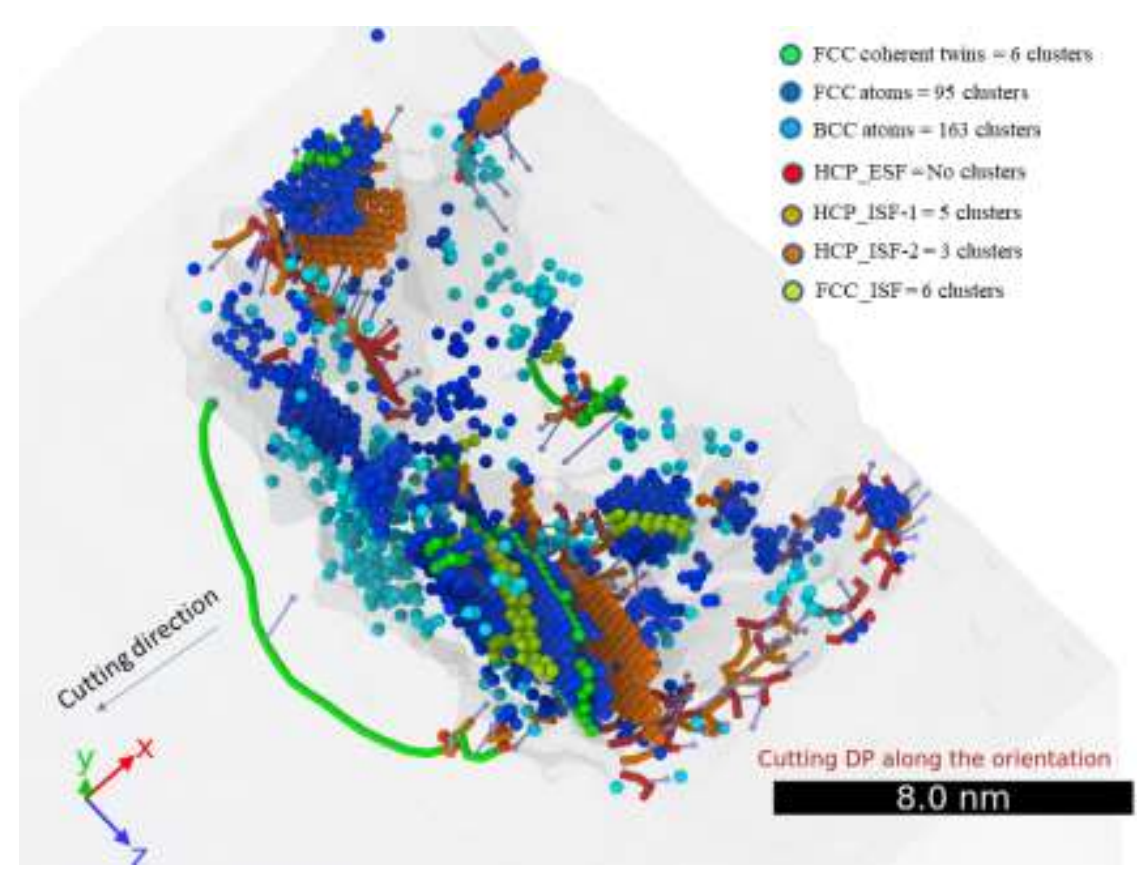

(b)

Figure 11: Isometric view of nanoscratching simulations showing directional dependency during cutting the Mg crystal with the presence of DP regions (a) when cutting was performed across the DPs and (b) when cutting was performed along the DPs. Planar defects such as FCC coherent twins, HCP extrinsic stacking fault, HCP Intrinsic faults and FCC intrinsic faults in varying volume may be noticed. 


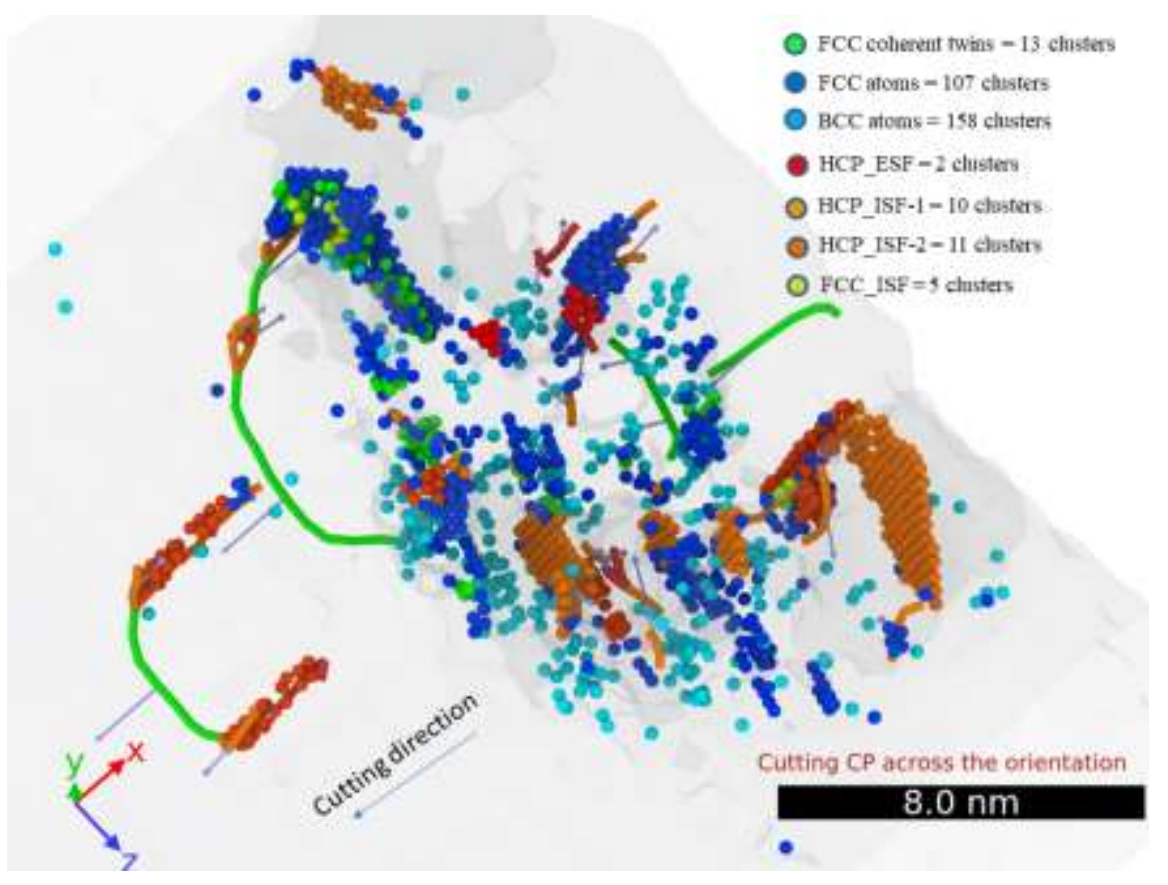

(a)

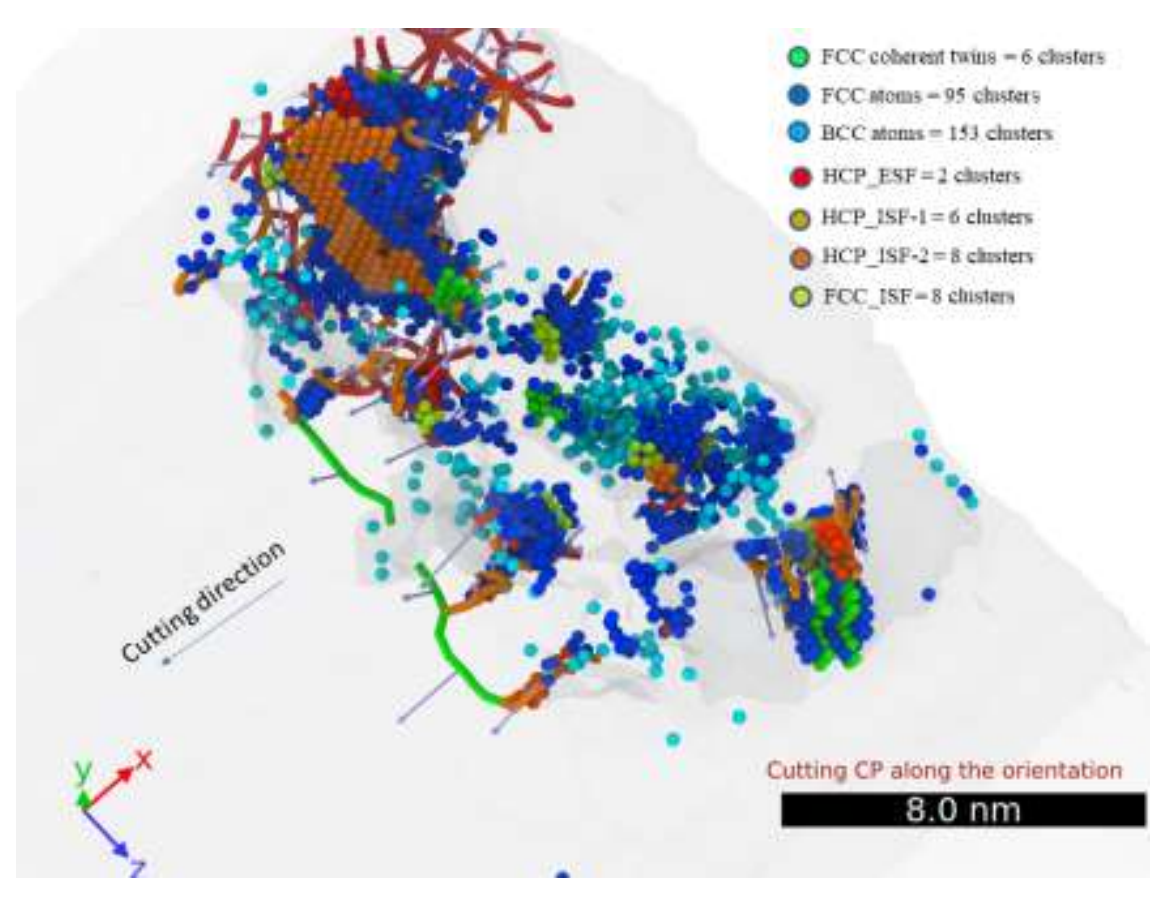

(b)

Figure 12: Isometric view of nanoscratching simulations showing directional dependency during cutting the Mg crystal with the presence of $\mathrm{CP}$ regions (a) when cutting was performed across the CPs and (b) when cutting was performed along the CPs. Planar defects such as FCC 
coherent twins, HCP extrinsic stacking fault, HCP Intrinsic faults and FCC intrinsic faults in varying volume may be noticed.

The majority of the defects seen from the MD simulation were metastable transitions such as transformation of $\mathrm{HCP}$ atom to FCC and BCC atoms highlighted in dark and light blue respectively. Apart from this, there were locations identified that showed formation of FCC coherent twin structures highlighted in green colour. These defects were not only limited to the area of scratching but a lot of these defects were along the side of the scratch whereby the stress field does not attain the sufficient peak for the material to flow and in some cases, the side flow or piled up structures also showed additional types of faults in the regular crystal structure. The other forms of defects observed were associated with Intrinsic stacking fault and Extrinsic stacking faults and the degree of these faults in case of DP's and CP's being scratched across and along the direction varied in each case. Planar defects result from the propagation of partial dislocations such as intrinsic stacking faults (SF). A particular SF type ISF_1 in HCP metals is said to be related to the emission of partials with Burgers vectors $b=1 / 6<\overline{2} 203>$ while type ISF_2 is related to the emission of $1 / 3<\overline{1} 100>$. ISF_1 can be seen as a defect in the stacking of the basal plane sequence in an hcp crystal where the ideal stacking sequence ABABABABA changes to ABABCBCB while in an ISF_2 this sequence changes to ABABCACA [14]. Also, metals such as Mg have a SF energy for the basal plane that is smaller than for the prismatic planes and hence the preference for glide is for basal slip, where the critical resolved shear stress (CRSS) is smaller. An illustrative detail of each of these defect is presented further in Figure 13.

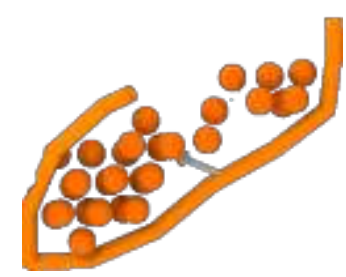

(a)

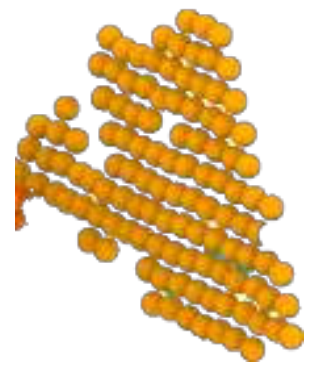

(b)

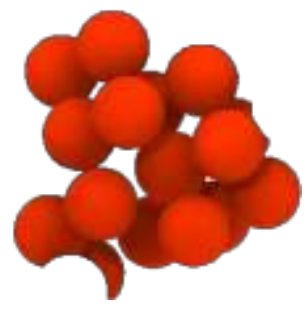

(c)

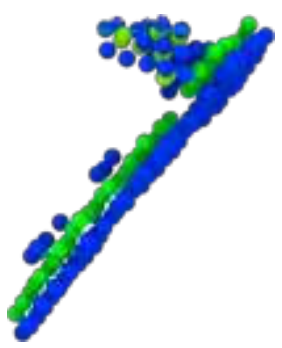

(d)

Figure 13. Different planar defects of pure $\mathrm{Mg}$ extracted from the MD simulation: (a) HCP_ISF_2 defect, (b) HCP_ISF_1 defect, (c) HCP_ESF defect and (d) FCC coherent twin.

Table IV provides a quantifiable insights on the number of these defect clusters extracted 
from the simulation. The general observation was that the number of defects observed during cutting across the direction of precipitates were far more compared to precipitates scratched along their direction of lay. Furthermore, it can be seen that the HPC_ISF type 1 defects were maximum when DP region was cut across the precipitates whereas the FCC coherent twins formation was maximal while cutting across the precipitates and it was independent of the type of precipitate cut.

Table IV: Summary of planar defects categorised by the number of clusters in a given scratch length (volume) of cut made in four cases

\begin{tabular}{|c|c|c|c|c|}
\hline Defect details & $\begin{array}{c}\text { Cutting DP } \\
\text { across the } \\
\text { precipitates }\end{array}$ & $\begin{array}{c}\text { Cutting DP } \\
\text { along the } \\
\text { precipitates }\end{array}$ & $\begin{array}{c}\text { Cutting CP } \\
\text { across the } \\
\text { precipitates }\end{array}$ & $\begin{array}{c}\text { Cutting CP } \\
\text { along the } \\
\text { precipitates }\end{array}$ \\
\hline FCC coherent twins & 11 & 6 & 13 & 6 \\
\hline $\begin{array}{c}\text { HCP_external } \\
\text { stacking fault }\end{array}$ & 1 & No ESF & 2 & 2 \\
\hline $\begin{array}{c}\text { HCP_ISF type 1 } \\
(b=1 / 6<-2203>)\end{array}$ & 20 & 5 & 10 & 8 \\
\hline $\begin{array}{c}\text { HCP_ISF type 2 } \\
(b=1 / 3<-1100>)\end{array}$ & 6 & 3 & 11 & 8 \\
\hline FCC_ISF & 12 & 6 & 5 & \\
\hline
\end{tabular}

\subsubsection{Scratch forces and friction ratio}

The normal (Fy) and lateral forces (Fy) along with coefficient of friction (COF) were plotted in Figure 14. The average normal force for pure $\mathrm{Mg}$, DP and $\mathrm{CP}$ regions was observed to be of similar magnitude during scratching of substrates in all cases but a huge variation in the lateral force was observed that contributed to the observed change in COF also shown in figure 14. 
Figure 14 shows that scratch direction does not have any effect on normal force in two cases i.e. DP and CP regions along and across the precipitates. The significant differences in lateral forces were observed and thus COF was different in all the three cases. Pure Mg was observed to have the highest $\mathrm{COF}$ as compared to $\mathrm{DP}$ and $\mathrm{CP}$ regions. Also, the anisotropy in $\mathrm{COF}$ in case of DP and CP regions was also observed, while scratching along and across the precipitate regions. DP and CP regions both showed high $\mathrm{COF}$, while scratching across the precipitate regions. The area fraction of precipitates in case of DP regions is higher than the $\mathrm{CP}$ regions. Thus, DP regions shows higher COF as compared to $\mathrm{CP}$ regions.

One may note here that the values of Fx, Fy and COF are likely to be influenced by the choice of a hypothetical imaginary indenter made in this work. The fact is that the use of imaginary indenter (such as the one used in this study) creates a purely repulsive force normal to the direction of the substrate and its surface is frictionless. Beside, MD conditions were such that the tests were made in vacuum. These situation leads to an overestimated forces compared to when modelling a real diamond indenter and this aspect was recently highlighted by the authors [37]. In light of this, it is safe to say that the main inference from figure 14 should be that the DPs showed higher COF than the CP's but their absolute value depicted in figure 14 may be subjected to change based on more realistic modelling conditions.

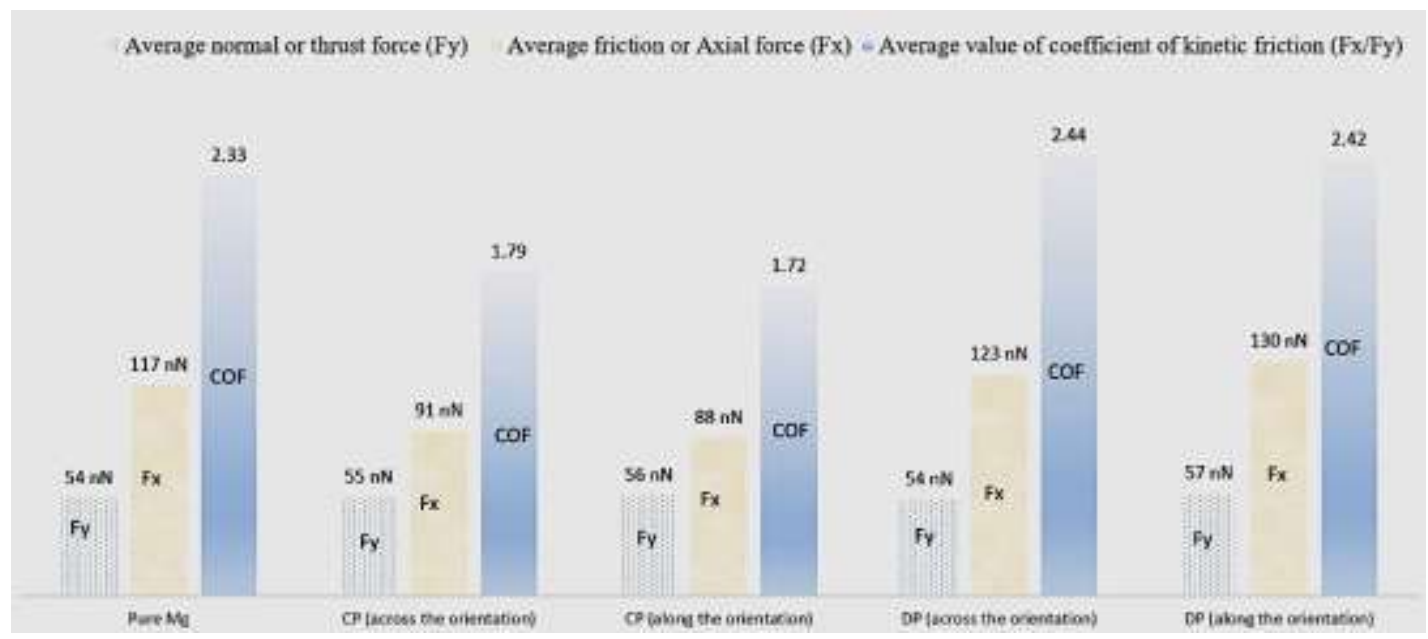

Figure 14. Value of forces and coefficient of kinetic friction extracted from the MD simulation. 


\subsection{Combined view from experiments and simulations}

From nano scratch experiments and MD simulation, it was observed that precipitate morphology and alignment has a significant effect on materials deformation. Pure $\mathrm{Mg}$ in general showed least wear resistance which corroborated with the higher volume of dislocation based plasticity as confirmed from the MD simulations. Further, the ease of wear in CP regions as compared to DP regions can be understood by considering higher activity of basal $<\mathrm{a}>$ type of dislocations (Table III). The combined observations also suggest that cutting across the direction of precipitates (both for CP and DP) was dominated by the generation of planar defects whereas cutting along the direction of precipitates was dominated by dislocation burst. Moreover, the higher wear resistance for cutting across the precipitate than cutting along the precipitate might be related with enhanced precipitate-dislocation interaction in cutting across the direction. This is consistent with MD results presented above where higher dislocation activity was seen during scratching along the precipitates.

\section{Conclusions}

In the present study, friction and wear response of precipitate containing AZ91 alloy was examined using experimental nanoscratch testing and using state-of-the-art MD simulations. Nanoscratch experiments suggested that wear resistance of pure $\mathrm{Mg}$ was significantly lower than $\mathrm{CP}$ and DP regions and that the DP regions showed higher wear resistance than the CP regions. Also, twining activity in DP regions was absent. These observations can be rationalised by considering the quantitative analysis of dislocation activities beneath the scratch surface. The ease of wear is consistent with higher dislocation activity. Further, MD simulation results also suggest that scratching DP regions across the precipitate has higher scratch resistance than along the precipitates. One might relate this to difficulty in dislocation nucleation owing to enhanced dislocation-precipitate interaction. The COF value for DP regions was observed to be higher than $\mathrm{CP}$ regions irrespective of scratching direction. Also, 
scratching across the precipitates resulted in higher COF compared to scratching along the direction of precipitates regardless of their type (CP or DP)

\section{Acknowledgments:}

JJ would like to thank financial assistance received from Faculty Interdisciplinary Research Project (FIRP), IIT Delhi. NNG would like to acknowledge SERB (ECR/2016/001014) for financial support. Authors also acknowledge the overall support received from Department of Materials Science and Engineering, IIT Delhi in maintaining the research infrastructure. Special thanks to Dr Alexander Stukowski (Developer of OVITO) for his useful advices in the drafting stage of the manuscript. Computational work was carried out in the Centre for Doctoral Training in Ultra-Precision, which is supported by the UKRI via Grants No.: EP/K503241/1 and EP/L016567/1. MD calculations were performed on the Isambard Bristol, UK and ARCHER HPC of the UK supercomputing service accessed by Resource Allocation Panel (RAP) grant. SG is particularly grateful to the fantastic financial support provided by the UKRI (Grant No. EP/S013652/1, EP/T001100/1, EP/T024607/1 and EP/S036180/1), H2020 (Cost Actions (CA15102, CA18125, CA18224 and CA16235) and EURAMET EMPIR A185 (2018)), Royal Academy of Engineering (Grant No. IAPP18-19\295), and Newton Fellowship award from the Royal Society (NIF\R1\191571).

\section{References}

[1] B.L. Mordike, T. Ebert, Magnesium Properties - applications - potential, Mater. Sci. Eng. A. 302 (2001) 37-45. https://doi.org/10.1016/S0921-5093(00)01351-4.

[2] Y.X. Zhao, P.E. Irving, A. Cini, Hardness environments around fatigued scratches in clad and unclad 2024 T351 aluminium alloy, Mater. Sci. Eng. A. 500 (2009) 16-24. https://doi.org/10.1016/j.msea.2008.09.039. 
[3] S.K. 3. Zhang, C. X., Chen, P. L., Chen, H. J., SHI, A. J., \& GUANG, Application and research progress of magnesium alloys in automobile industry, Foundry Technol. (2008) 29(4), 531. http://en.cnki.com.cn/Article_en/CJFDTotal-ZZJS200804025.htm (accessed December 10, 2019).

[4] G. Cole, Mg components for automotive body, chassis, and powertrain, (1997).

[5] J. feng Huang, H. yan Yu, Y. bing Li, H. Cui, J. ping He, J. shan Zhang, Precipitation behaviors of spray formed AZ91 magnesium alloy during heat treatment and their strengthening effect, Mater. Des. 30 (2009) 440-444. https://doi.org/10.1016/j.matdes.2008.06.001.

[6] P.J. Blau, M. Walukas, Sliding friction and wear of magnesium alloy AZ91D produced by two different methods, Tribol. Int. 33 (2000) 573-579. https://doi.org/10.1016/S0301-679X(00)00108-0.

[7] W. Huang, C. Du, Z. Li, M. Liu, W. Liu, Tribological characteristics of magnesium alloy using N-containing compounds as lubricating additives during sliding, Wear. 260 (2006) 140-148. https://doi.org/10.1016/j.wear.2004.12.039.

[8] J. An, R.G. Li, Y. Lu, C.M. Chen, Y. Xu, X. Chen, L.M. Wang, Dry sliding wear behavior of magnesium alloys, Wear. 265 (2008) 97-104. https://doi.org/10.1016/j.wear.2007.08.021.

[9] A. Barylski, M. Kupka, K. Aniołek, J. Rak, The effect of precipitation hardening on the structure and mechanical and tribological properties of magnesium alloy WE54, Vacuum. 139 (2017) 77-86. https://doi.org/10.1016/j.vacuum.2017.02.015.

[10] K. Amini, A. Akhbarizadeh, S. Javadpour, Investigating the effect of quench environment and deep cryogenic treatment on the wear behavior of AZ91, Mater. Des. 
54 (2014) 154-160. https://doi.org/10.1016/j.matdes.2013.07.051.

[11] P. Nautiyal, J. Jain, A. Agarwal, Influence of Microstructure on Scratch-Induced Deformation Mechanisms in AZ80 Magnesium Alloy, Tribol. Lett. 61 (3) (2016) 29. https://doi.org/10.1007/s11249-016-0649-z.

[12] I. 12. Christian, The Theory of Transformations in Metals and Alloys, Pergamon Press. Oxford. 179 (1965) 816.

[13] D. Duly, J.P. Simon, Y. Brechet, On the competition between continuous and discontinuous precipitations in binary MgAl alloys, Acta Metall. Mater. 43 (1995) 101-106. https://doi.org/10.1016/0956-7151(95)90266-X.

[14] A.F. Crawley, B. Lagowski, EFFECT OF TWO-STEP AGING ON THE PRECIPITATE STRUCTURE IN MAGNESIUM ALLOY AZ91., Met. Trans. 5 (1974) 949-951. https://doi.org/10.1007/BF02643153.

[15] N. Stanford, J. Geng, Y.B. Chun, C.H.J. Davies, J.F. Nie, M.R. Barnett, Effect of plate-shaped particle distributions on the deformation behaviour of magnesium alloy AZ91 in tension and compression, Acta Mater. 60 (2012) 218-228. https://doi.org/10.1016/j.actamat.2011.10.001.

[16] V. Jain, R.S. Mishra, A.K. Gupta, Gouthama, Study of B-precipitates and their effect on the directional yield asymmetry of friction stir processed and aged AZ91C alloy, Mater. Sci. Eng. A. 560 (2013) 500-509. https://doi.org/10.1016/j.msea.2012.09.095.

[17] W.J. Lai, Y.Y. Li, Y.F. Hsu, S. Trong, W.H. Wang, Aging behaviour and precipitate morphologies in Mg-7.7Al-0.5Zn-0.3Mn (wt.\%) alloy, J. Alloys Compd. 476 (2009) 118-124. https://doi.org/10.1016/j.jallcom.2008.08.043. 
[18] Q. Chen, K. Li, Y. Liu, Z. Zhao, K. Tao, Q. Zhu, Effects of heat treatment on the wear behavior of surfacing AZ91 magnesium alloy, J. Mater. Res. 32 (2017) 2161-2168. https://doi.org/10.1557/jmr.2017.186.

[19] T. Ohmura, S. Matsuoka, K. Tanaka, T. Yoshida, Nanoindentation load-displacement behavior of pure face centered cubic metal thin films on a hard substrate, Thin Solid Films. 385 (2001) 198-204. https://doi.org/10.1016/S0040-6090(00)01907-6.

[20] R.B. Aronson, Why dry machining?, Manuf. Eng. January. (1995).

[21] V. Yamakov, D. Wolf, S.R. Phillpot, A.K. Mukherjee, H. Gleiter, Dislocation processes in the deformation of nanocrystalline aluminium by molecular-dynamics simulation, Nat. Mater. 1 (2002) 45-48. https://doi.org/10.1038/nmat700.

[22] R. Komanduri, N. Chandrasekaran, L.M. Raff, MD simulation of indentation and scratching of single crystal aluminum, Wear. 240 (2000) 113-143. https://doi.org/10.1016/S0043-1648(00)00358-6.

[23] D. Mulliah, D. Christopher, S.D. Kenny, R. Smith, Nanoscratching of silver ( $\left.\begin{array}{lll}1 & 0 & 0\end{array}\right)$ with a diamond tip, in: Nucl. Instruments Methods Phys. Res. Sect. B Beam Interact. with Mater. Atoms, 2003: pp. 294-299. https://doi.org/10.1016/S0168$583 X(02) 01872-4$

[24] T.H. Fang, C.H. Liu, S.T. Shen, S.D. Prior, L.W. Ji, J.H. Wu, Nanoscratch behavior of multi-layered films using molecular dynamics, Appl. Phys. A Mater. Sci. Process. 90 (2008) 753-758. https://doi.org/10.1007/s00339-007-4351-8.

[25] J.J. Zhang, T. Sun, A. Hartmaier, Y.D. Yan, Atomistic simulation of the influence of nanomachining-induced deformation on subsequent nanoindentation, Comput. Mater. Sci. 59 (2012) 14-21. https://doi.org/10.1016/j.commatsci.2012.02.024. 
[26] Y. Gao, C.J. Ruestes, H.M. Urbassek, Nanoindentation and nanoscratching of iron: Atomistic simulation of dislocation generation and reactions, Comput. Mater. Sci. 90 (2014) 232-240. https://doi.org/10.1016/j.commatsci.2014.04.027.

[27] C. Lu, Y. Gao, G. Michal, H. Zhu, N.N. Huynh, A.K. Tieu, Molecular Dynamic Simulation of Effect of Crystallographic Orientation on Nano-Indentation/Scratching Behaviors of BCC Iron, in: Adv. Tribol., Springer Berlin Heidelberg, 2009: pp. 562563. https://doi.org/10.1007/978-3-642-03653-8_181.

[28] M.M. Biener, J. Biener, A.M. Hodge, A. V. Hamza, Dislocation nucleation in bcc Ta single crystals studied by nanoindentation, Phys. Rev. B - Condens. Matter Mater. Phys. 76 (16) (2007) 165422. https://doi.org/10.1103/PhysRevB.76.165422.

[29] S. Groh, E.B. Marin, M.F. Horstemeyer, D.J. Bammann, Dislocation motion in magnesium: A study by molecular statics and molecular dynamics, Model. Simul. Mater. Sci. Eng. 17 (2009) 075009. https://doi.org/10.1088/0965-0393/17/7/075009.

[30] R. Matsumoto, M. Uranagase, N. Miyazaki, Molecular Dynamics Analyses of Deformation Behavior of Long-Period-Stacking-Ordered Structures, Mater. Trans. 54 (2013) 686-692. https://doi.org/10.2320/matertrans.MI201211.

[31] Z. Wu, W.A. Curtin, The origins of high hardening and low ductility in magnesium, Nature. 526 (2015) 62-67. https://doi.org/10.1038/nature15364.

[32] I. Alabd Alhafez, C.J. Ruestes, Y. Gao, H.M. Urbassek, Nanoindentation of hcp metals: a comparative simulation study of the evolution of dislocation networks, 27 (4) (2016) 045706. https://doi.org/10.1088/0957-4484/27/4/045706.

[33] I. Alabd Alhafez, H.M. Urbassek, Scratching of hcp metals: A molecular-dynamics study, Comput. Mater. Sci. 113 (2016) 187-197. 
https://doi.org/10.1016/j.commatsci.2015.11.038.

[34] S. Jun, Y. Lee, S.Y. Kim, S. Im, Large-scale molecular dynamics simulations of Al(111) nanoscratching, Nanotechnology. 15 (2004) 1169-1174. https://doi.org/10.1088/0957-4484/15/9/011.

[35] A.C. Fischer-Cripps, Introduction to Contact Mechanics, Springer US, Boston, MA, 2007. https://doi.org/10.1007/978-0-387-68188-7.

[36] G.M. Pharr, An improved technique for determining hardness and elastic modulus using load and displacement sensing indentation experiments, J. Mater. Res. 7 (1992) 1564-1583. https://doi.org/10.1557/JMR.1992.1564.

[37] S. Goel, G. Cross, A. Stukowski, E. Gamsjäger, B. Beake, A. Agrawal, Designing nanoindentation simulation studies by appropriate indenter choices: Case study on single crystal tungsten, Comput. Mater. Sci. 152 (2018) 196-210. https://doi.org/10.1016/j.commatsci.2018.04.044.

[38] B.D. Beake, S. Goel, Incipient plasticity in tungsten during nanoindentation: Dependence on surface roughness, probe radius and crystal orientation, Int. J. Refract. Met. Hard Mater. 75 (2018) 63-69. https://doi.org/10.1016/j.ijrmhm.2018.03.020.

[39] S. Plimpton, Fast parallel algorithms for short-range molecular dynamics, J. Comput. Phys. 117 (1995) 1-19. https://doi.org/10.1006/jcph.1995.1039.

[40] A. Stukowski, Visualization and analysis of atomistic simulation data with OVITO-the Open Visualization Tool, Model. Simul. Mater. Sci. Eng. 18 (2010) 015012. https://doi.org/10.1088/0965-0393/18/1/015012.

[41] A. Stukowski, V. V. Bulatov, A. Arsenlis, Automated identification and indexing of 
dislocations in crystal interfaces, Model. Simul. Mater. Sci. Eng. 20 (2012) 085007. https://doi.org/10.1088/0965-0393/20/8/085007.

[42] A. Stukowski, K. Albe, Extracting dislocations and non-dislocation crystal defects from atomistic simulation data, Model. Simul. Mater. Sci. Eng. 18 (2010) 085001. https://doi.org/10.1088/0965-0393/18/8/085001.

[43] X.Y. Liu, J.B. Adams, F. Ercolessi, J.A. Moriarty, EAM potential for magnesium from quantum mechanical forces, Model. Simul. Mater. Sci. Eng. 4 (1996) 293-303. https://doi.org/10.1088/0965-0393/4/3/004.

[44] M.I. Mendelev, M. Asta, M.J. Rahman, J.J. Hoyt, Development of interatomic potentials appropriate for simulation of solid-liquid interface properties in $\mathrm{Al}-\mathrm{Mg}$ alloys, Philos. Mag. 89 (2009) 3269-3285. https://doi.org/10.1080/14786430903260727.

[45] B. Jelinek, S. Groh, M.F. Horstemeyer, J. Houze, S.G. Kim, G.J. Wagner, A. Moitra, M.I. Baskes, Modified embedded atom method potential for $\mathrm{Al}, \mathrm{Si}, \mathrm{Mg}, \mathrm{Cu}$, and $\mathrm{Fe}$ alloys, Phys. Rev. B - Condens. Matter Mater. Phys. 85 (2012) 245102. https://doi.org/10.1103/PhysRevB.85.245102.

[46] Y.M. Kim, N.J. Kim, B.J. Lee, Atomistic Modeling of pure Mg and Mg-Al systems, Calphad Comput. Coupling Phase Diagrams Thermochem. 33 (2009) 650-657. https://doi.org/10.1016/j.calphad.2009.07.004.

[47] A. Moitra, J. LLorca, Atomistic simulations of dislocation/precipitation interactions in Mg-Al alloys and implications for precipitation hardening, (2017). http://arxiv.org/abs/1704.03487 (accessed December 10, 2019).

[48] S. Goel, B. Beake, C.W. Chan, N. Haque Faisal, N. Dunne, Twinning anisotropy of 
tantalum during nanoindentation, Mater. Sci. Eng. A. 627 (2015) 249-261. https://doi.org/10.1016/j.msea.2014.12.075.

[49] M. Zhang, P.M. Kelly, Crystallography of Mg 17 Al 12 precipitates in AZ91D alloy, 48 (2003) 647-652.

[50] J.F. Archard, Contact and rubbing of flat surfaces, J. Appl. Phys. 24 (1953) 981-988. https://doi.org/10.1063/1.1721448.

[51] J. Dryzek, E. Dryzek, The subsurface zone in magnesium alloy studied by positron annihilation techniques, 40 (2007) 1360-1368. https://doi.org/10.1016/j.triboint.2007.03.004.

[52] R. Liu, L. De Yin, J.T. Wang, The effect of precipitation on the mechanical properties of extruded AZ80, in: Magnes. Technol., 2012: pp. 555-559. https://doi.org/10.1007/978-3-319-48203-3_98.

[53] J.B. Clark, Age hardening in a Mg-9 wt.\% Al alloy, Acta Metall. 16 (1968) 141-152. https://doi.org/10.1016/0001-6160(68)90109-0.

[54] M.A. Gharghouri, G.C. Weatherly, J.D. Embury, The interaction of twins and precipitates in a Mg-7.7 at.\% Al alloy, Philos. Mag. A Phys. Condens. Matter, Struct. Defects Mech. Prop. 78 (1998) 1137-1149. https://doi.org/10.1080/01418619808239980.

[55] S.R. Agnew, D.W. Brown, C.N. Tomé, Validating a polycrystal model for the elastoplastic response of magnesium alloy AZ31 using in situ neutron diffraction, Acta Mater. 54 (2006) 4841-4852. https://doi.org/10.1016/j.actamat.2006.06.020.

[56] A. Jain, O. Duygulu, D.W. Brown, C.N. Tom, S.R. Agnew, Grain size effects on the 
tensile properties and deformation mechanisms of a magnesium alloy, AZ31B, sheet, 486 (2008) 545-555. https://doi.org/10.1016/j.msea.2007.09.069.

\section{Appendix}

Table I: Properties of Beta $\mathrm{Mg}_{17} \mathrm{Al}_{12}$ and pure $\mathrm{Mg}$ obtained from the MD simulation at $0 \mathrm{~K}$ using Finnis-Sinclair (EAM) potential function

\begin{tabular}{|c|c|c|}
\hline & Beta- $\mathrm{Mg}_{17} \mathrm{Al}_{12}$ & $\begin{array}{c}\text { Pure Magnesium } \\
\text { (HCP) }\end{array}$ \\
\hline Equilibrium lattice constant $(\AA ̊ \AA)$ & 10.54 & 3.184 \\
\hline Elastic constants $(\mathrm{GPa})$ & $\begin{array}{l}\mathbf{C}_{11}=\mathbf{C}_{22}=\mathbf{C}_{33}=138 \\
\mathbf{C}_{12}=\mathbf{C}_{13}=\mathbf{C}_{23}=46.5 \\
\mathbf{C}_{44}=\mathbf{C}_{55}=\mathbf{C}_{66}=28\end{array}$ & $\begin{array}{c}C_{11}=C_{22}=68.79 \\
C_{13}=C_{23}=15.99 \\
C_{44}=C_{55}=12.75 \\
C_{33}=69.52 \\
C_{12}=26.09 \\
C_{66}=21.35\end{array}$ \\
\hline Zener anisotropy ratio $\frac{C_{11}-C_{12}}{2 \times C_{44}}$ & 1.62 & 1.68 \\
\hline
\end{tabular}




\begin{tabular}{|c|c|c|}
\hline $\begin{array}{l}\text { Young's modulus on the (100) } \\
\text { orientation (GPa) } C_{11}-2 \frac{C_{12}}{C_{11}+C_{12}} C_{12}\end{array}$ & 114.65 & 54.4 \\
\hline $\begin{array}{l}\text { Young's modulus on the (110) } \\
\text { orientation (GPa) } \\
4 \frac{\left(C_{11}{ }^{2}+C_{12} C_{11}-2 C_{12}{ }^{2}\right) C_{44}}{2 C_{44} C_{11}+C_{11}{ }^{2}+C_{12} C_{11}-2 C_{12}{ }^{2}}\end{array}$ & 82.52 & 32.9 \\
\hline $\begin{array}{l}\text { Young's modulus on the (111) } \\
\text { orientation (GPa) } 3 \frac{C_{44}\left(C_{11}+2 C_{12}\right)}{C_{11}+2 C_{12}+C_{44}}\end{array}$ & 75.47 & 34.58 \\
\hline $\begin{array}{l}\text { Shear modulus }(\mathrm{G})(\mathrm{GPa}) \\
\frac{C_{11}-C_{12}+C_{44}}{3}\end{array}$ & 39.94 & 18.48 \\
\hline Shear strength $(\mathrm{G} / 2 \pi)(\mathrm{GPa})$ & 6.36 & 2.94 \\
\hline $\begin{array}{l}\text { Voigt Poisson's ratio } \\
\frac{C_{11}+4 C_{12}-2 C_{44}}{4 C_{11}+6 C_{12}+2 C_{44}}\end{array}$ & 0.30 & 0.32 \\
\hline $\begin{array}{l}\text { Voigt Bulk Modulus(B) (GPa) } \\
\frac{\left(C_{11}+C_{22}+C_{33}\right)+2\left(C_{12}+C_{13}+C_{23}\right)}{9} \text { or } \\
\frac{\left(C_{11}+2 C_{12}\right)}{3} \text { for isotropic }\end{array}$ & 77.02 & 35.91 \\
\hline
\end{tabular}


2020-02-28

Towards an improved understanding of plasticity, friction and wear mechanisms in precipitate containing AZ91 Mg alloy

\section{Kumar, Deepak}

\section{Elsevier}

Kumar D, Goel S, Gosvami NN, et al., (2020) Towards an improved understanding of plasticity, friction and wear mechanisms in precipitate containing AZ91 Mg alloy. Acta Materialia, Volume 10, May 2020, Article number 100640 https://doi.org/10.1016/j.mtla.2020.100640

Downloaded from Cranfield Library Services E-Repository 